\title{
Evaluation of the effect of various prior creep-fatigue interaction damages on subsequent tensile and creep properties of $9 \% \mathrm{Cr}$ steel
}

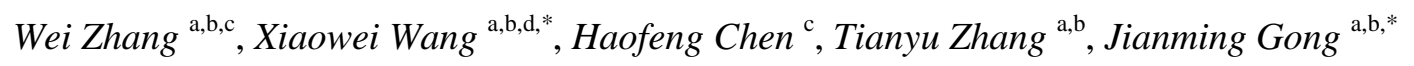

${ }^{a}$ School of Mechanical and Power Engineering, Nanjing Tech University, Nanjing, 211816, China

${ }^{\mathrm{b}}$ Jiangsu Key Lab of Design and Manufacture of Extreme Pressure Equipment, Nanjing, 211816, China

${ }^{\mathrm{c}}$ Department of Mechanical and Aerospace Engineering, University of Strathclyde, Glasgow, G1 1XJ, UK

${ }^{\mathrm{d}}$ Faculty of Engineering and Architecture, Ghent University, Zwijnaarde, B-9052, Belgium

*Corresponding authors:

E-mail: xwwang@njtech.edu.cn (X.Wang); gongjm@njtech.edu.cn (J.Gong)

Tel.: +8625 58139361; Fax: +862558139361.

\section{ABSTRACT}

The degradation of tensile and creep properties is inevitable during high temperature service operation.

Hence this work aims to evaluate the effect of prior creep-fatigue interaction damages on remnant tensile and creep properties of $9 \% \mathrm{Cr}$ steel. Prior creep-fatigue tests interrupted at different lifetime fractions and different tensile hold times are performed at $650{ }^{\circ} \mathrm{C}$. Afterwards, subsequent tensile and creep tests are conducted at the same temperature. Results reveal that high lifetime fraction of prior creep-fatigue loading leads to obvious reduction of remnant tensile strength and creep resistance. However, the increase in tensile hold time hardly alters the remnant properties. Microstructure and fracture surface observations indicate that the deterioration of remnant tensile strength is mainly ascribed to the decline of dislocation density occurred during prior creep-fatigue process, whereas the growth of martensite lath plays the dominated role in the reduction of remnant creep resistance. Moreover, surface crack also accelerates the decline of creep resistance at high lifetime fraction. To quantify the prior creep-fatigue interaction damage, a fatigue damage 
indicator is proposed. Determined relationships between remnant tensile, creep properties and defined fatigue damage are obtained.

Key words: Prior creep-fatigue loading; Remnant tensile and creep properties; Microstructure; Damage indicator.

\section{Introduction}

At high temperature, the deterioration of material properties is inevitable, especially when components are subjected to complicated loadings simultaneously [1]. Among these loadings, low cycle fatigue (LCF) and creep-fatigue interaction (C-F) are the most common damage modes [2-5], which are frequently encountered by the components serviced in modern fossil fuel and nuclear power plants due to frequent start-ups, shut-downs and other possible fluctuations [6, 7]. Regarding the material properties, tensile and creep properties are the primary characters to be considered during the high temperature component design. Therefore, it is significant to evaluate the effect of prior fatigue loading on remnant tensile and creep properties to ensure the safety of high temperature components. Previous works have revealed that the material tensile and creep properties could be altered by prior LCF loading [8-26]. However, the studies about the influence of prior C-F loading on subsequent tensile and creep properties are still limited.

Rubio et al. [8-11] investigated the effect of prior LCF loading on subsequent tensile behavior of 6061-T6 aluminum alloy and AISI 4140T steel and found that the tensile deformation of 6061-T6 aluminum alloy kept relatively stable despite the prior LCF was introduced, while the prior LCF significantly reduced the tensile strength of AISI 4140T steel. Mocko et al. [12-14] found that the yield stress and ultimate stress of DP500 steel could be increased by stress-controlled prior LCF loading and he also proposed a constitutive model to predict the uniaxial tensile behavior after LCF loading [15, 16]. Shankar et al. [17-19] further pointed out that both LCF and C-F loading degraded the tensile strength of modified 9Cr-1Mo steel and the 
increase of temperature led to additional decline of tensile properties. Regarding the remnant creep properties after prior fatigue loading, the prior LCF generally accelerates the creep rate and reduces the creep life of Cr-Mo steel [20-24]. It is also shown that the damage level of prior LCF is temperature [25], cycle number [23] and strain amplitude [26] dependent. However, to the best of the authors' knowledge, the influence of various prior C-F loadings on subsequent tensile and creep properties has not been elucidated yet. In our previous work [27], it is concluded that increasing tensile hold time from $0 \mathrm{~s}$ to $600 \mathrm{~s}$ at $600{ }^{\circ} \mathrm{C}$ results in $70 \%$ reduction of fatigue life, which suggests that the remnant material properties may be related to the tensile hold time. Consequently, the effect of different hold times prior C-F loadings on subsequent tensile and creep properties should be clarified.

Among many materials, $9 \% \mathrm{Cr}$ ferritic steel has been widely used in the structures of the fossil fuel and nuclear power plants due to the high fatigue and creep strength, good weld ability and high thermal conductivity at elevated temperature [28, 29]. In this study, strain controlled C-F tests at various tensile hold times are conducted and interrupted at the same lifetime fraction. Afterwards, subsequent tensile and creep tests are performed on the same specimens to investigate the remnant properties. Finally, fracture surface and microstructure observations are carried out to characterize the damage mechanisms of prior C-F loading. To quantify the prior C-F damage, a fatigue damage indicator is proposed and quantitative relationships between the defined fatigue damage and the remnant tensile and creep properties are determined.

\section{Experimental procedures}

\subsection{Material}

This study focuses on a circumferentially P92 steel pipe. A pipe with an outer diameter of $105 \mathrm{~mm}$ and a wall thickness of $24 \mathrm{~mm}$ was supplied in the as-received state of normalized and tempered condition. The chemical compositions of the investigated P92 steel pipe are listed in wt\%: $0.106 \mathrm{C} ; 0.361 \mathrm{Mn} ; 0.235 \mathrm{Si}$; 
0.017 P; 0.0081S; $9.18 \mathrm{Cr} ; 0.368 \mathrm{Mo} ; 0.182 \mathrm{~V} ; 0.061 \mathrm{~N} ; 0.108 \mathrm{Ni} ; 0.0059 \mathrm{Al} ; 0.078 \mathrm{Nb} ; 1.85 \mathrm{~W} ; 0.0022 \mathrm{~B}$;

Bal. Fe. Fig. 1 shows the optical (a) and TEM (b) micrographs of the as-received state. It can be observed that the as-received P92 steel consists of prior austenite grains, blocks, packets, precipitates and martensite laths. The detailed microstructure is schematically shown in Fig. 2 and Leen et al. [30] have pointed out that these microstructures were the main contributors to the excellent fatigue and creep performances of $9 \% \mathrm{Cr}$ steel. Cylindrical specimens with $25 \mathrm{~mm}$ gauge length and $8 \mathrm{~mm}$ gauge diameter were machined from the pipe along the axial direction, as shown in Fig. 3. Specimens used for the C-F test and the following tensile and creep tests have all the same geometrical dimensions.

\subsection{Prior C-F and subsequent tensile and creep tests}

Test procedure can be divided into three steps: C-F lifetime determination test, interrupted prior C-F test and subsequent tensile and creep tests. Schematic representation of the C-F lifetime determination test and the interrupted prior C-F, subsequent tensile and creep tests are shown in Figs. 4 and 5, respectively.

(1) Determination of C-F lifetime: to acquire the prior C-F specimens with various tensile hold times and various lifetime fractions, the C-F lifetime, $N_{\mathrm{f}}$, at different tensile hold times (ranging from $0 \mathrm{~s}$ to $600 \mathrm{~s}$ ) should be determined primarily. Reference specimens were C-F tested to failure in total-strain control mode with a constant strain rate of $1 \times 10^{-3} \mathrm{~s}^{-1}$. These C-F tests were conducted in accordance with the ASTM E2714 standard [31]. To keep consistent with our previous works [26, 34], the strain amplitude of $0.4 \%$ was adopted. Deformation in the specimen gauge length was measured by a high temperature extensometer produced by Epsilon. Regarding the dispersion of C-F lifetime, at least three tests were carried out at each hold time. However, the shortest C-F lifetime was adopted for the subsequent tests to prevent the possible premature fracture. The method to determine the C-F lifetime is presented in Fig. 4 (inserted figure), which has been elaborately discussed in our previous work [35]. 
(2) Interrupted prior C-F test: according to the C-F lifetime determined in the first step, new specimens were then C-F tested and interrupted at different lifetime fractions, i.e. 10\%, 20\%, 50\% and 70\%, as shown in Fig. 5 (blue line).

(3) Subsequent tensile and creep tests: after the prior C-F test, the prior C-F exposure specimens were tensile and creep tested to fracture, as shown in Fig. 5 (red line). Tensile tests were conducted under displacement control of $0.025 \mathrm{~mm} / \mathrm{s}$ according to ASTM E8 standard [32]. Creep tests were carried out at $130 \mathrm{MPa}$ according to ASTM E139 standard [33]. All of the tests were performed in air at $650{ }^{\circ} \mathrm{C}$ and the temperature was controlled within $\pm 2{ }^{\circ} \mathrm{C}$. Detailed test conditions and results are listed in Table 1 .

\subsection{Microstructure observation}

After the subsequent tensile and creep fracture, specimen surface crack and fractographs were observed by a Zeiss Axio Imager A1m optical microscopy (OM) and a JSM-6360LV scanning electron microscopy (SEM), respectively. A JEOL JEM-2010 transmission electron microscope (TEM) was utilized for the microstructure characterization. TEM samples for the microstructure observation were extracted from transverse section of the tested specimens. Martensite lath width was measured from the TEM micrographs with the linear intercept method by counting all clearly visible lath boundaries. The martensite lath width presented in the study was averaged from at least twenty measured results.

\section{Experimental results}

\subsection{Peak tensile stress during prior $C-F$}

It has been revealed that $9 \% \mathrm{Cr}$ steel exhibits continuous cyclic softening as C-F progresses [36, 37]. In regard to the studied P92 steel, peak tensile stress recorded during C-F process is plotted in Figs. 4 and 6. Comparison of peak tensile stress between different hold times illustrates that long hold time results in low 
peak tensile stress and short C-F lifetime, as shown in Fig. 4. It is also noteworthy that all the peak tensile stresses of prior C-F tests almost overlap with the total lifetime C-F tests, as shown in Fig. 6, which manifests the good repeatability of these interrupted C-F tests. Moreover, the peak tensile stress of C-F test displays three softening stages: initial rapid softening stage, subsequent linear stable stage and final accelerated stage. The microstructure evolutions have been identified as the main reason for the observed cyclic softening behavior [38, 39], which is illustrated in the following paragraph.

\subsection{Microstructure evolution during prior $C-F$}

Figs. 7 and 8 show the TEM micrographs at different lifetime fractions of $180 \mathrm{~s}$ hold time and TEM micrographs at $20 \%$ lifetime fraction of different hold times, respectively. An overall observation shows that recovery of the martensite lath is obvious due to the growth of subgrains. Meanwhile, the dislocation networks [40] appear inside the martensite laths, indicating the significant depletion of dislocation density [41]. These microstructure evolutions are recognized to be related to the cyclic softening as presented in Figs. 4 and 6 [42]. Detailed observation on Fig. 7 further shows that the increasing in lifetime fraction drives martensite lath transforms to lower energy structure, such as cells or equiaxed structure. As the lifetime fraction reaches $70 \%$ (Figs. 7(d)), the cells or equiaxed structure is dominant. Apart from the observed growth of martensite lath and the decrease of dislocation density, precipitates coarsening may also take place during long-term high temperature experiment. Nevertheless, no appreciable coarsening of precipitates occurs in the present study, because the precipitate coarsening is strongly time-dependent and the longest prior C-F test period $(32 \mathrm{~h})$ in the present work is relatively short. This is also in agreement with the results obtained by Gopinath et al. [43] and Xuan et al. [37]. Further comparison of microstructures between different hold times of $20 \%$ lifetime fraction (Figs. 7(b) and 8) gives an indication that martensite lath and 
dislocation density barely change with increasing hold time. It manifests that within $600 \mathrm{~s}$, length of hold time has little effect on the microstructure evolution.

\subsection{Remnant tensile properties}

Figs. 9(a) and (b) respectively depict the tensile curves after various lifetime fractions of $180 \mathrm{~s}$ hold time and tensile curves after $20 \%$ lifetime fraction of different hold times. Note that the tensile curves after various lifetime fractions of $180 \mathrm{~s}$ hold time show similar shape, except the tensile curve after $70 \%$ lifetime fraction. In addition, the increase in lifetime fraction leads to serious degraded behavior of tensile properties. By contrast, tensile curves after various hold times almost overlap, which indicates the period of hold time has little effect on subsequent tensile properties. The relationships between tensile properties, lifetime fraction and hold time are shown in Fig. 10 and listed in Table 1. Figs. 10(a) and (b) depict the varied behaviors of $0.2 \%$ offset yield stress and ultimate tensile stress with respect to lifetime fraction and hold time, respectively. It is shown that existence of prior C-F exposure decreases the yield stress and the ultimate tensile stress for all prior C-F loading conditions. The trend of the decreased tensile strength with respect to lifetime fraction (Figs. 10(a)) is similar to the first stage and second stage of the cyclic softening curve shown in Figs. 4 and 6. As lifetime fraction increases, the tensile strength decreases continuously and rapid decreasing behavior can be observed before $20 \%$ lifetime fraction. Afterwards, the yield stress and ultimate tensile stress decrease linearly with increasing lifetime fraction. Nevertheless, the increase in hold time barely introduces additional degradation on the tensile strength, as shown in Fig. 10(b). The yield stress and the ultimate tensile stress almost keep constant at $240 \mathrm{MPa}$ and $270 \mathrm{MPa}$, respectively, regardless of the variation of hold time. In regard to the elongation and uniform elongation (Figs. 10(c) and (d)), their variations show different behaviors with respect to lifetime fraction and hold time. Degeneration of elongation happens with increasing lifetime fraction. By contrast, the increase of hold time slightly enhances 
the elongation. Furthermore, it is interesting to see that the increase in the lifetime fraction and the hold time leads to the increased uniform elongation, as shown in blue line of Figs. 10(c) and (d). This is in agreement with the result of ultrafine grain or nanostructured materials $[44,45]$. Since the uniform elongation and tensile strength are dominantly affected by the microstructure [46] while the elongation is not only relative to the microstructure but also the conditions of specimen surface [19], the combined effect of microstructure and specimen surface modification after prior C-F loading should be therefore deserved more attention.

\subsection{Remnant creep properties}

The effects of lifetime fraction and hold time of prior C-F loading on subsequent creep curves are shown in Fig. 11. An overview of these creep curves reveals that the prior C-F loading doesn't change the creep deformation shape. The creep curves still consist of three stages: primary stage, secondary stable stage and tertiary accelerated stage. However, significant degradation of creep resistance due to prior C-F loading was observed on both various lifetime fractions (Fig. 11(a)) and various hold times (Fig. 11(b)). The creep life and creep rupture strain are different at various lifetime fractions, as shown in Fig. 11(a). Whereas, the creep curves at various hold times do not present much difference, as shown in Fig. 11(b). Yet the creep resistances at various hold times are still lower than that of the as-received condition, which is also consistent with the observation of tensile curves shown in Fig. 9(b). Quantitative descriptions of the creep properties are depicted in Figs. 12 and 13 and listed in Table 1. Figs. 12(a) and (b) show the varied behaviors of creep life and reduction of creep life with respect to lifetime fraction and hold time, respectively. It is evident that creep life decreases a lot after prior C-F loading in comparison with the as-received state. The decreased behavior of creep life at different lifetime fractions shows three distinct stages: initial slow stage, subsequent accelerated stage and final stable stage. The sharp reduction in creep life appears between $20 \%$ and $50 \%$ lifetime fraction. This is different from the tensile properties shown in Fig. 10(a). Further observation on Fig. 
12(a) manifests that the creep life tends to be saturated as the lifetime fraction continuously increases. This phenomenon is similar to the prior LCF effect as discussed in our previous work [26]. Regarding the effect of hold time period, as shown in Fig. 12(b), the creep life and the reduction of creep life still keep almost unchanged, which are about $875 \mathrm{~h}$ and $23.5 \%$, respectively. To further illuminate the effect of prior C-F loading on subsequent creep strength, creep rate curves at different lifetime fractions and different hold times are compared, as shown in Fig. 13. An overview of these curves evidences that there is an obvious difference between secondary and tertiary creep stages. The prior C-F loading accelerates the creep rate of secondary and tertiary creep stages. However, prior C-F loading has no significant impact on creep rate in the first creep stage. In addition, the creep rate increases with increasing lifetime fraction, as shown in Figs. 13(a) and (c). The variations of creep rate and the minimum creep rate with respect to hold time (Figs. 13(b) and (d)) still verify that increasing in hold time hardly introduces additional damage on subsequent creep properties.

\subsection{Fractograph observation}

It has been reported that high temperature fatigue loading not only induces microstructure evolution but also alters the surface features $[18,19]$. In our previous studies, surface alternation due to prior LCF has also been discussed, in which the surface crack did not appear [26, 47]. However, since the C-F damage on surface modification is generally higher than that of the LCF loading [27, 48], whether the surface crack is produced or not during prior C-F process is still unclear. Therefore, the cross section micrographs near fracture location of the tensile failed specimens are investigated, as shown in Fig. 14. Evident surface cracks are noticed at $50 \%$ and $70 \%$ lifetime fractions due to the serious slip band and surface oxidation at high lifetime fraction [19]. However, comparison between Figs. 14(d)-(f) shows that hold time period does not obviously affect the surface crack formation, which demonstrates that the effect of the increase in lifetime fraction is larger than that of hold time. These phenomena can also be noticed on creep failed specimens 
presented in Fig. 15. Comparison of surfaces between tensile failed specimens and creep failed specimens indicates that the oxidation of creep failed specimens is severer due to the long-term duration of creep process. It is also noteworthy that the surface cracks after subsequent creep loading are more visible, as shown in Figs. 15(b) and (c). More interesting thing is that a lot of creep voids distribute near the surface crack tips. It may be deduced that surface crack accelerates the formation and coalescence of micro voids during the subsequent creep process. Consequently, the effect of surface crack on the tensile and creep properties should not be neglected and the surface cracks contribute to the variation of tensile elongation and the rapid reduction of creep properties.

To demonstrate the effect of surface crack, Fig. 16 and Fig. 17 display the fractographs of the tensile failed and creep failed specimens, respectively. The presence of dimples indicates typical ductile fracture [49]. Comparison of fractographs between various hold times (Figs. 16-17(d), (e) and (f)) shows that no obvious change occurs on the fractured surface, dimple size keeps similar. However, detailed observation seems to present a slight oxidation of the fracture surface, especially increasing in lifetime fraction and hold time leads to the additional oxidation. Moreover, it can be seen that after $50 \%$ and $70 \%$ lifetime fractions of $180 \mathrm{~s}$ hold time (Figs. 16(b) and (c)), the tensile fracture surface shows a mixed fracture character (ductile mode and shear mode). Generally, the shear mode and ductile mode should not occur simultaneously in the same zone during uniaxial tensile test. Nevertheless, the surface crack shown in Fig. 14 may lead to multiaxial stress state which contributes to the mixed fracture mode. Furthermore, the tensile results shown in Fig. 10(a) suggests that the surface cracks are not big enough to obviously affect the yield stress and ultimate tensile stress, since the yield stress and ultimate tensile stress are measured from the uniform deformation of tensile process, in which the effect of surface crack can be neglected. Whereas, the elongation mainly determined by the necking process is dramatically decreased by the surface crack. Consequently, the 
effect of surface crack on yield stress and ultimate tensile stress can be neglected, and the elongation is related to the surface crack can be concluded. Regarding the creep fracture surfaces shown in Fig. 17, in comparison with the tensile fracture surface, the oxidation of creep fracture surface is more evident. It is in agreement with the observation shown in Fig. 15. However, even after the $70 \%$ lifetime fraction of $180 \mathrm{~s}$ hold time, the creep crack initiation mode does not change. Furthermore, an overview of fracture surface in Figs. 17(b) and (c) presents a brittle fracture mode near the specimen surface, which also verifies the influence of surface crack on the creep deformation.

\section{Discussion}

\subsection{Relationship between prior $C-F$ damage and remnant properties}

According to the LCF damage definition in our previous work [34], its suitability for quantifying C-F damage is evaluated here. The defined fatigue damage indicator $D_{\mathrm{f}}$ is expressed as

$$
D_{\mathrm{f}}=\frac{\varepsilon_{i n}^{n}-\varepsilon_{i n}^{0}}{\varepsilon_{i n}^{f}-\varepsilon_{i n}^{0}}
$$

where $D_{\mathrm{f}}$ is the defined fatigue damage, $\varepsilon_{i n}^{0}, \varepsilon_{i n}^{f}$ and $\varepsilon_{i n}^{n}$ are the initial inelastic strain range at the first cycle, the inelastic strain range at the fracture cycle and the studied cycle. Figs. 18(a) and (b) respectively depict the variation of inelastic strain range and defined fatigue damage during C-F process at different hold times. It is shown that the inelastic strain range and the defined fatigue damage present similar behavior at different hold times. Both the inelastic strain range and the defined fatigue damage evolutions consist of two obvious stages: initial rapid increasing stage followed by a relatively stable increasing stage. Obtained damages of prior C-F tests are listed in Table 1. The relations between yield stress, ultimate tensile stress and creep life with the defined prior C-F damage are shown in Fig. 19. It shows that both the yield stress and ultimate tensile stress display a linear relationship with the defined prior C-F damage irrespective of the 
lifetime fraction and hold time, as shown in Figs. 19(a) and (b). The relationship between yield stress and the defined prior C-F damage can be obtained by the least-squares linear regression and given as

$$
\sigma_{\mathrm{y}}=-102.7 D_{\mathrm{f}}+320
$$

where $\sigma_{\mathrm{y}}$, is the yield stress with unit of MPa. Similarly, the relationship between ultimate tensile stress and defined prior C-F damage can also be obtained by the least-squares linear regression and given as

$$
\sigma_{\mathrm{UTS}}=-96.7 D_{\mathrm{f}}+338
$$

where $\sigma_{\mathrm{UTS}}$ is the ultimate tensile stress with unit of MPa. It is interesting to find that the Eqs. (2) and (3) are the same with previous LCF study [34], which verifies that our proposed fatigue damage indicator can account for various fatigue loadings. Additionally, Fig. 19(c) presents the evolution of creep life with respect to the defined prior C-F damage. It shows that the creep life displays two linear stages with the defined prior C-F damage and it is different from the evolution of tensile strength shown in Figs. 19(a) and (b). Detailed observation on the evolution of creep life indicates that the reduction of creep life in the first stage is relatively slow, whereas the reduction of creep life in the second stage is rapid. This phenomenon is consistent with the experimental results shown in Figs. 11 and 12. The combined effect of microstructure evolution (Figs. 7 and 8) and surface crack (Fig. 15) occurred during prior C-F process could explain the phenomenon, which will be specifically discussed in the next section. Moreover, the relationship between creep life and defined prior C-F damage can be expressed as

$$
\begin{aligned}
& t_{\mathrm{c} 1}=-347 D_{\mathrm{f}}+1167 \quad\left(D_{\mathrm{f}}<0.8\right) \\
& t_{\mathrm{c} 2}=-4443 D_{\mathrm{f}}+4457\left(D_{\mathrm{f}}>0.8\right)
\end{aligned}
$$

where creep life $t_{\mathrm{c} 1}$ and $t_{\mathrm{c} 2}$ have unit of $\mathrm{h}$.

\subsection{Damage mechanisms of prior $C-F$ loading}


It is achieved above that the relationships between the defined prior C-F damage and remnant tensile and creep properties show different behaviors. Therefore, it is necessary to clarify the reason for this difference from point of view of the microstructure damage. On the one hand, it is documented that the C-F properties of $9 \% \mathrm{Cr}$ steel are mainly determined by its martensitic microstructures: grain boundaries, dislocation substructures and precipitates [30], as shown in Fig. 2. However, these complex microstructures are altered during cyclic deformation. The as-received fine martensite laths and subgrains (Fig. 1) show a vanish behavior due to the disappearance of (sub)boundaries during the C-F progress, especially the low angle boundaries (LABs), as shown in Figs. 7 and 8. Simultaneously, the elimination of dislocation in these LABs takes place, which is manifested by the appearance of the dislocation network [41] shown in Figs. 7 and 8. In addition, coarsening of precipitates may also happen at long-term high temperature experiment, however, this is not the case for the current study because the longest time of prior C-F exposure is about 32 $\mathrm{h}$, which is too short. On the other hand, considering that the high tensile and creep strengths of $9 \% \mathrm{Cr}$ steel are also dependent on the fine martensitic structures [50-52], the degradation of subsequent mechanical properties are therefore reasonable attributed to the reduction of effective structures ((sub)boundaries and dislocation density) during prior C-F loading. Additionally, the effect of surface crack (Figs. 14 and15) due to prior C-F loading should not be excluded. The tensile strength has been revealed to be inversely proportional to the width of martensite lath, which is well known as Hall-Petch strengthening effect [53-55]. The measured width of martensite lath at different lifetime fractions is shown in Figs. 20(a). It can be seen that increasing in lifetime fraction induces the coarsening of martensite lath width and the variation of martensite lath width nearly presents a linear behavior, which is quite different from the tensile strength evolution (Figs. 9 and 10). Therefore, the recovery of martensite lath is not the predominant damage mechanism for the degeneration of subsequent tensile properties, and then the effect of dislocation density 
should be considered. Unfortunately, due to the limited access to measuring the dislocation density during prior C-F process, reported data from literatures [30, 52, 56, 57-61] are used here. The evolution of dislocation density with respect to the lifetime fraction of $1800 \mathrm{~s}$ hold time is shown in Fig. 20 (c). As it can be seen, the dislocation density is high in the as-received condition, which contributes to the initial high tensile strength. During C-F process, the dislocation density decreases and shows two different stages: a rapid decline stage followed by a stable stage. This evolution behavior is consistent with the initial stage of cyclic softening (Figs. 4 and 6) and the degradation trend of yield stress and ultimate tensile stress (Fig. 10(a)). It is therefore reasonable to deduce that the consumption of dislocation density dominates the degradation of subsequent yield stress and ultimate tensile stress. In addition, the reduced dislocation density can also explain the higher uniform elongation presented in Fig. 10(c). Owing to the low dislocation density after prior C-F, additional deformation may be required to trigger the dislocation movement and produce new dislocations to reach the ultimate tensile strength during subsequent tensile deformation [46]. Accordingly, a higher uniform elongation is evidenced.

In regard to the creep properties, the creep life decreases slowly before $20 \%$ lifetime fraction, as shown in Figs. 11-13. During this period, no obvious surface crack is detected (Fig. 15(a)), the width of martensite lath grows tardily (Fig. 20(a)) while the dislocation density decreases rapidly (Fig. 20(c)). Normally, rapid reduction of dislocation density should lead to evident degradation of deformation resistance [62, 63]. However, according to Figs. 11-13, the creep strength is slightly affected by the reduction of dislocation density, which demonstrates that the creep strength is sensitive to the width of martensite lath rather than the dislocation density. Thus, the slow growth of martensite lath mainly contributes to the degradation of subsequent creep properties in this duration. From $20 \%$ to $50 \%$ lifetime fraction, the dislocation density hardly alters while obvious growth of martensite lath occurs (Fig. 20). The coarsening of meartensite lath 
shows a linear tendency, meanwhile, the surface crack starts to form because of the formation of slip bands and surface oxidation. Therefore, the martensite lath combined with the limited effect of small surface crack dominate the degradation of subsequent creep properties in this duration. As the lifetime fraction increases, apart from the recovery of martensite lath (Fig. 20(a)), the distinctive propagation of surface crack occurs, as presented in Figs. 15(b) and (c). The damage mechanism of prior C-F starts to transform to the combined effect of microstructure evolution and obvious surface crack. For better clarification of the associated features, the local magnifications of crack tips in Figs. 15(b) and (c) are shown in Figs. 21(a) and (b), respectively. Numerous intergranular creep voids (identified by red arrows) are evidenced near the tips of fatigue cracks (identified by yellow arrows). Simultaneous appearance of both fatigue surface crack and creep voids near the surface crack tips suggests that fatigue surface crack assists the initiation of creep voids and the growth of creep crack during the following long-term creep process. During creep process, the microstructure modification in prior C-F process facilitate creep voids initiation, especially near the surface crack tips due to the large local plastic deformation. Thereby, creep voids tend to initiate both in the specimen and near the surface crack tips simultaneously. Afterwards, these creep voids present a tendency to link together in subsequent creep exposure and the creep voids near surface crack tips unavoidably connect with the fatigue cracks (identified by white arrows in Fig. 21(b), named fatigue-creep crack), which eventually accelerates the creep damage (Figs. 11-13) and contributes to the mixed fracture model shown in Fig. 17(b) and (c). Consequently, creep life was reduced more evidently due to the combined effect of microstructure and obvious surface crack, and two linear variation stages of creep life were caused as shown in Fig. 19(c). The detailed process of these mechanisms is schematically depicted in Fig. 22.

Regarding the effect of hold time, the microstructures at $20 \%$ lifetime fraction of different hold times do not present much difference (Figs. 20(b) and (d)), and no surface crack was induced even hold time 
increases to $600 \mathrm{~s}$. As a consequence, the influence of various hold times prior C-F loadings on subsequent tensile and creep properties remains similar, as shown in Figs. 9-13. However, further increase in hold time of C-F loading may induce severer surface oxidation and precipitate coarsening [64], which will play an important role in cyclic softening and remnant properties. Therefore, prolonged prior C-F tests should be further conducted to investigate the effect of surface oxidation and precipitate in the future.

\section{Conclusions}

In the present study, the influence of prior C-F damage on remnant tensile and creep properties of $9 \% \mathrm{Cr}$ steel was evaluated. Prior C-F loadings at various hold times and various lifetime fractions were introduced to clarify the damage mechanisms. Through this work following conclusions can be drawn:

(1) Remnant tensile and creep properties are degraded by prior C-F loading. The increase in lifetime fraction induces more damage than the increase in hold time. The degradation of subsequent tensile yield stress and ultimate tensile stress presents two stages with respect to lifetime fraction, while remnant creep life displays three stages. Prior C-F loading leads subsequent creep properties saturated after 50\% lifetime fraction.

(2) Reduction of dislocation density during prior C-F dominates the degradation of subsequent tensile yield stress and ultimate tensile stress, whereas the growth of martensite lath plays the primary role in the reduction of creep resistance. Furthermore, surface crack formed in prior C-F also accelerates the decline of creep strength at high lifetime fraction. The increase in hold times hardly alters the microstructure and the remnant properties.

(3) The defined fatigue damage indicator can give a good description for C-F damage. Both yield stress and ultimate tensile stress vary linearly with the defined fatigue damage, in spite of the lifetime fraction and 
hold time. However, due to the additional effect of surface crack, the evolution of creep life shows two linear stages behavior with respect to the defined fatigue damage.

\section{Acknowledgements}

The authors gratefully acknowledge the financial support of the National Key R\&D Program of China (No. 2018YFC0808800), innovation program for graduate students in Jiangsu Province of China (No. KYCX17_0935) and China Postdoctoral Science Foundation (No. 2016M600405). We also thank Mr. Yinong Lyu from School of Material Science and Engineering, Nanjing Tech University, for his help with the TEM specimens' preparation and observation.

\section{References}

[1] Vasudevan AK, Sadananda K, Iyyer N. Fatigue damage analysis: Issues and challenges. Int J Fatigue 2016;82:120-133.

[2] Wang RZ, Zhang XC, Gong JG, Zhu XM, Tu ST. Creep-fatigue life prediction and interaction diagram in nickel-based GH4169 superalloy at 650 C based on cycle-by-cycle concept. Int J Fatigue 2017;97:114-123.

[3] Wang RZ, Zhang XC, Tu ST, Zhang CC. The effects of inhomogeneous microstructure and loading waveform on creep-fatigue behaviour in a forged and precipitation hardened nickel-based superalloy. Int J Fatigue 2017;97:190-201. [4] Farragher TP, Scully S, O’Dowd NP, Leen SB. Development of life assessment procedures for power plant headers operated under flexible loading scenarios. Int J Fatigue 2013;49:50-61.

[5] Kang G, Liu Y. Uniaxial ratchetting and low-cycle fatigue failure of the steel with cyclic stabilizing or softening feature. Mater Sci Eng, A 2008;472:258-268.

[6] Shankar V, Valsan M, Rao KBS, Kannan R, Mannan SL, Pathak SD. Low cycle fatigue behavior and microstructural evolution of modified 9Cr-1Mo ferritic steel. Mater Sci Eng, A 2006;437:413-422.

[7] Benjamin F, Maxime S, Alexandra R, Françoise B, André P. Microstructural evolutions and cyclic softening of 9\% Cr martensitic steels. J Nucl Mater 2009;386:71-74.

[8] Sánchez-Santana U, Rubio-González C, Mesmacque G, Amrouche A. Effect of fatigue damage on the dynamic tensile behavior of 6061-T6 aluminum alloy and AISI 4140T steel. Int J Fatigue 2009;31:1928-1937. 
[9] Sánchez-Santana U, Rubio-González C, Mesmacque G, Amrouche A, Decoopman X. Effect of fatigue damage induced by cyclic plasticity on the dynamic tensile behavior of materials. Int J Fatigue 2008;30:1708-1719.

[10] Sánchez-Santana U, Rubio-González C, Mesmacque G, Amrouche A, Decoopman X. Dynamic tensile behavior of materials with previous fatigue damage. Mater Sci Eng, A 2008;497:51-60.

[11] Rubio-González C, Gallardo-González JA, Mesmacque G, Sanchez-Santana U. Dynamic fracture toughness of pre-fatigued materials. Int J Fatigue 2008;30:1056-1064.

[12] Moćko W. The influence of stress-controlled tensile fatigue loading on the stress-strain characteristics of AISI 1045 steel. Mater Des 2014;58:145-153.

[13] Moćko W, Kowalewski ZL. Evolution of tensile properties of the TiAl6V4 alloy due to the prior cyclic loading history. J Theor App Mech 2014;52:847-851.

[14] Moćko W, Janiszewski J, Grązka M. Application of an extended Rusinek-Klepaczko constitutive model to predict the mechanical behavior of 6082-T6 aluminum under Taylor impact test conditions. J Strain Anal Eng 2013;48:364-375.

[15] Moćko W, Grzywna P, Kowalewski ZL., Radziejewska J. An influence of cyclic loading on the form of constitutive relationship for DP500 steel. Mater Des 2006;103:183-193.

[16] Moćko W, Kruszka L. A viscoplastic response of a dual phase steel exposed to prior cyclic loadings. Mech Mater 2017;113:126-135.

[17] Mariappan K, Shankar V, Sandhya R, Mathew MD, Bhaduri AK. Influence of prior fatigue damage on tensile properties of 316L (N) stainless steel and modified 9Cr-1Mo steel. Metall Mater Trans A 2015;46:989-1003.

[18] Mariappan K, Shankar V, Sandhya R, Bhaduri AK, Laha K. A Comparative Evaluation of the Effect of Low Cycle Fatigue and Creep-Fatigue Interaction on Surface Morphology and Tensile Properties of 316L(N) Stainless Steel. Metall Mater Trans A 2016;47:1575-1586.

[19] Mariappan K, Shankar V, Sandhya R, Bhaduri AK, Laha K. Comparative assessment of remnant tensile properties of modified 9Cr-1Mo steel under prior low cycle fatigue and creep-fatigue interaction loading. Int $\mathrm{J}$ Fatigue 2017;103:342-352.

[20] Chaudhuri S, Ghosh RN. Creep behavior of 2.25 Cr1Mo steel-Effects of thermal ageing and pre-strain. Mater Sci Eng, A 2009;510:136-141.

[21] Fournier B, Sauzay M, Caës C, Noblecourt M, Mottot M, Allais L, et al. Creep-fatigue interactions in a 9 pct Cr-1 pct Mo martensitic steel: Part I. Mechanical test results. Metall Mater Trans A 2009;40:321-329. 
[22] Erinosho TO, Venkata KA, Mostafavi M, Knowles DM, Truman CE. Influence of prior cyclic plasticity on creep deformation using crystal plasticity modelling. Int J Solids Struct 2018;139:129-137.

[23] Sarkar A, Vijayanand VD, Parameswaran P, Shankar V, Sandhya R, Laha K, et al. Influence of prior fatigue cycling on creep behavior of reduced activation ferriticmartensitic steel. Metall Mater Trans A 2014;45:3023-3035.

[24] Takahashi Y. Prediction of deformation and failure of modified 9Cr-1Mo steel under creep-fatigue interaction. Mater High Temp 2012;29:280-292.

[25] Binda L, Holdsworth SR, Mazza E. Influence of prior cyclic deformation on creep properties of 1CrMoV. Mater High Temp 2010;27:21-27.

[26] Zhang W, Wang XW, Li X, Gong JM, Wahab MA. Influence of prior low cycle fatigue on microstructure evolution and subsequent creep behavior. Int J Fatigue 2018;109:114-125.

[27] Wang XW, Zhang W, Gong JM, Wahab MA. Low cycle fatigue and creep fatigue interaction behavior of 9Cr-0.5 Mo-1.8 WV-Nb heat-resistant steel at high temperature. J Nucl Mater 2018;505:73-84.

[28] Wang N, Tu ST, Xuan FZ. A novel prediction method of creep rupture life of 9-12\% chromium ferritic steel based on abductive network. Eng Fail Anal 2013;31:302-310.

[29] Kral P, Dvorak J, Sklenicka V, Masuda T, Horita Z, Kucharova K, et al. Microstructure and creep behaviour of P92 steel after HPT. Mater Sci Eng, A 2018;723:287-295.

[30] Barrett RA, O'Donoghue PE, Leen SB. A physically-based constitutive model for high temperature microstructural degradation under cyclic deformation. Int J Fatigue 2017;100:388-406.

[31] ASTM standard E2714. Standard test method for creep-fatigue testing. ASTM international, West Conshohocken, PA, 2014.

[32] ASTM Standard E8. Standard test methods for tension testing of metallic materials. ASTM international, West Conshohocken, PA, 2004.

[33] ASTM Standard E139. Standard Test Methods for Conducting Creep, Creep-Rupture, and Stress-Rupture Tests of Metallic Materials, ASTM international, West Conshohocken, PA, 2011.

[34] Wang XW, Zhang W, Ni J, Zhang TY, Gong JM, Wahab, M. A. Quantitative description between pre-fatigue damage and residual tensile properties of P92 steel. Mater Sci Eng, A 2019;744:415-425.

[35] Wang XW, Gong JM, Zhao YP, Wang YF, Yu MH. Characterization of low cycle fatigue performance of new ferritic P92 steel at high temperature: Effect of strain amplitude. Steel Res Int 2015;86:1046-1055.

[36] Shankar V, Mariappan K, Sandhya R, Laha K, Bhaduri AK. Long term creep-fatigue interaction studies on India-specific reduced activation ferritic-martensitic (IN-RAFM) steel. Int J Fatigue 2017;98:259-268. 
[37] Zhang SL, Xuan FZ. Interaction of cyclic softening and stress relaxation of 9-12\% Cr steel under strain-controlled fatigue-creep condition: experimental and modeling. Int J Plast 2017;98:45-64.

[38] Zhang Z, Hu Z, Schmauder S, Mlikota M, Fan K. Low-cycle fatigue properties of P92 ferritic-martensitic steel at elevated temperature. J Mater Eng Perform 2016;25:1650-1662.

[39] Kim DW, Kim SS. Contribution of microstructure and slip system to cyclic softening of 9 wt.\% Cr steel. Int $\mathbf{J}$ Fatigue 2012;36:24-29.

[40] Moorthy V, Choudhary BK, Vaidyanathan S, Jayakumar T, Rao KBS, Raj B. An assessment of low cycle fatigue damage using magnetic Barkhausen emission in 9Cr-1Mo ferritic steel. Int J Fatigue 1999;21:263-269.

[41] Tian S, Zhou H, Zhang J, Yang H, Xu Y, Hu Z. Formation and role of dislocation networks during high temperature creep of a single crystal nickel-base superalloy. Mater Sci Eng, A 2000;279:160-165.

[42] Sauzay M, Brillet H, Monnet I, Mottot M, Barcelo F, Fournier B, Pineau A. Cyclically induced softening due to low-angle boundary annihilation in a martensitic steel. Mater Sci Eng, A 2005;400:241-244.

[43] Gopinath K, Gupta R K, Sahu J K, Ray PK, Ghosh RN. Designing P92 grade martensitic steel header pipes against creep-fatigue interaction loading condition: damage micromechanisms. Mater Des, 2015;86:411-420.

[44] Wang YM, Ma E. Strain hardening, strain rate sensitivity, and ductility of nanostructured metals. Mater Sci Eng, A 2004;375:46-52.

[45] Zhao YH, Bingert JF, Zhu YT, Liao XZ, Valiev RZ, Horita Z, et al. Tougher ultrafine grain Cu via high-angle grain boundaries and low dislocation density. Appl Phys Lett 2008;92: 081903.

[46] Wang YM, Ma E. Three strategies to achieve uniform tensile deformation in a nanostructured metal. Acta Mater, 2004;52:1699-1709.

[47] Zhang W, Wang XW, Gong JM, Jiang Y, Huang X. Experimental and simulated characterization of creep behavior of P92 steel with prior cyclic loading damage. J Mater Sci Technol 2017;33:1540-1548.

[48] Fournier B, Maxime S, Christel C, Michel N, Véronique R, Annick B, André P. High temperature creep-fatigue-oxidation interactions in 9-12\% Cr martensitic steels. J Nucl Mater 2009;386:418-421.

[49] Lee JS, Ghassemi Armaki H, Maruyama K, Muraki T, Asahi H. Causes of breakdown of creep strength in 9Cr-1.8W-0.5Mo-VNb steel. Mater Sci Eng, A 2006;428:270-5.

[50] Choudhary B K, Samuel E I, Sainath G, Christopher J, Mathew MD. Influence of temperature and strain rate on tensile deformation and fracture behavior of P92 ferritic steel. Metall Mater Trans A 2013;44:4979-4992.

[51] Giroux PF, Dalle F, Sauzay M, Malaplate J, Fournier B, Gourgues-Lorenzon AF. Mechanical and microstructural stability of P92 steel under uniaxial tension at high temperature. Mater Sci Eng, A 2010;527:3984-3993. 
[52] Ennis P J, Zielinska-Lipiec A, Wachter O, Czyrska-Filemonowicz A. Microstructural stability and creep rupture strength of the martensitic steel P92 for advanced power plant. Acta Mater 1997;45:4901-4907.

[53] Hansen N. Hall-Petch relation and boundary strengthening. Scripta Mater 2004;51:801-806.

[54] Wu D, Zhang J, Huang JC, Bei H, Nieh TG. Grain-boundary strengthening in nanocrystalline chromium and the Hall-Petch coefficient of body-centered cubic metals. Scripta Mater 2013;68:118-121.

[55] Yan P, Liu Z, Bao H, Weng Y, Liu W. Effect of normalizing temperature on the strength of 9Cr-3W-3Co martensitic heat resistant steel. Mater Sci Eng, A 2014;597:148-156.

[56] Chauhan A, Hoffmann J, Litvinov D, Aktaa J. High-temperature low-cycle fatigue behavior of a 9Cr-ODS steel: Part 1-pure fatigue, microstructure evolution and damage characteristics. Mater Sci Eng, A 2017;707:207-220.

[57] Brillet H. Comportement en Fatigue d'un acier a` $9 \% \mathrm{Cr}$ a $550{ }^{\circ} \mathrm{C}$. Note Technique CEA/DEN/DMN/SRMA 2003-2525, CEA, Saclay, France, 2003.

[58] Fournier B, Sauzay M, Barcelo F, Rauch E, Renault A, Cozzika T, et al. Creep-fatigue interactions in a 9 Pct Cr-1 Pct Mo martensitic steel: part II. Microstructural evolutions. Metall Mater Trans A 2009;40:330-341.

[59] Fournier B, Dalle F, Sauzay M, Longour J, Salvi M, Caës C, et al. Comparison of various 9-12\% Cr steels under fatigue and creep-fatigue loadings at high temperature. Mater Sci Eng, A 2011;528:6934-6945.

[60] Chauhan A, Hoffmann J, Litvinov D, Aktaa J. High-temperature low-cycle fatigue behavior of a 9Cr-ODS steel: part 2-hold time influence, microstructural evolution and damage characteristics. Mater Sci Eng, A 2018;730:197-206.

[61] Sauzay M, Fournier B, Mottot M, Pineau A, Monnet, I. Cyclic softening of martensitic steels at high temperature-Experiments and physically based modelling. Mater Sci Eng, A 2008;483:410-414.

[62] Takasawa K, Ikeda R, Ishikawa N, Ishigaki R. Effects of grain size and dislocation density on the susceptibility to high-pressure hydrogen environment embrittlement of high-strength low-alloy steels. Int J Hydrogen Energ 2012;37:2669-2675.

[63] Panait CG, Zielińska-Lipiec A, Koziel T, Czyrska-Filemonowicz A, Gourgues-Lorenzon AF, Bendick W. Evolution of dislocation density, size of subgrains and MX-type precipitates in a P91 steel during creep and during thermal ageing at $600 \mathrm{C}$ for more than 100,000 h. Mater Sci Eng, A 2010;527:4062-4069.

[64] Kimura M, Yamaguchi K, Hayakawa M, Kobayashi K, Kanazawa K.. Microstructures of creep-fatigued 9-12\% Cr ferritic heat-resisting steels. Int J Fatigue 2006;28:300-308. 
Table 1 Prior C-F and subsequent tensile and creep tests data at $650{ }^{\circ} \mathrm{C}$

\begin{tabular}{llllllllll}
\hline Test & $\begin{array}{l}\text { Hold } \\
\text { time }\end{array}$ & $\begin{array}{l}\text { Lifetime } \\
\text { fraction } \\
(\%)\end{array}$ & $\begin{array}{l}\text { Defined } \\
\text { damage }\end{array}$ & $\begin{array}{l}\text { Yield } \\
\text { stress } \\
(\mathrm{MPa})\end{array}$ & $\begin{array}{l}\text { Ultimate } \\
\text { tensile } \\
\text { stress } \\
(\mathrm{MPa})\end{array}$ & $\begin{array}{l}\text { Elongation } \\
(\%)\end{array}$ & $\begin{array}{l}\text { Uniform } \\
\text { Elongation } \\
(\%)\end{array}$ & $\begin{array}{l}\text { Creep } \\
\text { life } \\
(\mathrm{h})\end{array}$ & $\begin{array}{l}\text { Minimum } \\
\text { creep rate } \\
\left(\mathrm{h}^{-1}\right)\end{array}$ \\
\hline 1 & & & & & & & & \\
\hline & 0 & 20 & 0.73 & 252.0 & 272.0 & 35.0 & 1.952 & 864 & $2.230 \times 10^{-5}$ \\
3 & 30 & 20 & 0.73 & 245.5 & 267.4 & 36.2 & 2.648 & 833 & $2.349 \times 10^{-5}$ \\
4 & 180 & 10 & 0.61 & 248.5 & 272.6 & 36.1 & 2.443 & 1082 & $2.178 \times 10^{-5}$ \\
5 & 180 & 20 & 0.78 & 235.5 & 260.7 & 36.7 & 2.694 & 921 & $2.797 \times 10^{-5}$ \\
6 & 180 & 50 & 0.93 & 214.5 & 248.7 & 34.9 & 2.917 & 129 & $2.647 \times 10^{-4}$ \\
7 & 180 & 70 & 0.99 & 199.0 & 232.8 & 25.1 & 3.279 & 185 & $2.284 \times 10^{-4}$ \\
8 & 600 & 20 & 0.72 & 234.0 & 267.5 & 40.1 & 2.881 & 892 & $2.130 \times 10^{-5}$ \\
\hline
\end{tabular}



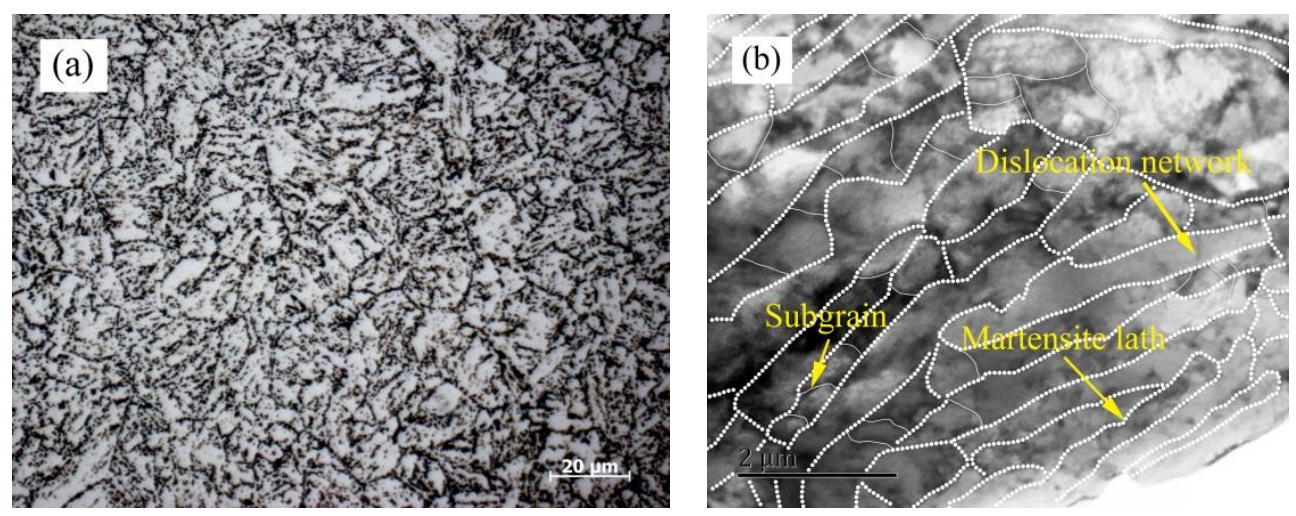

Fig. 1. (a) Optical and (b) TEM micrographs of the as-received P92 steel

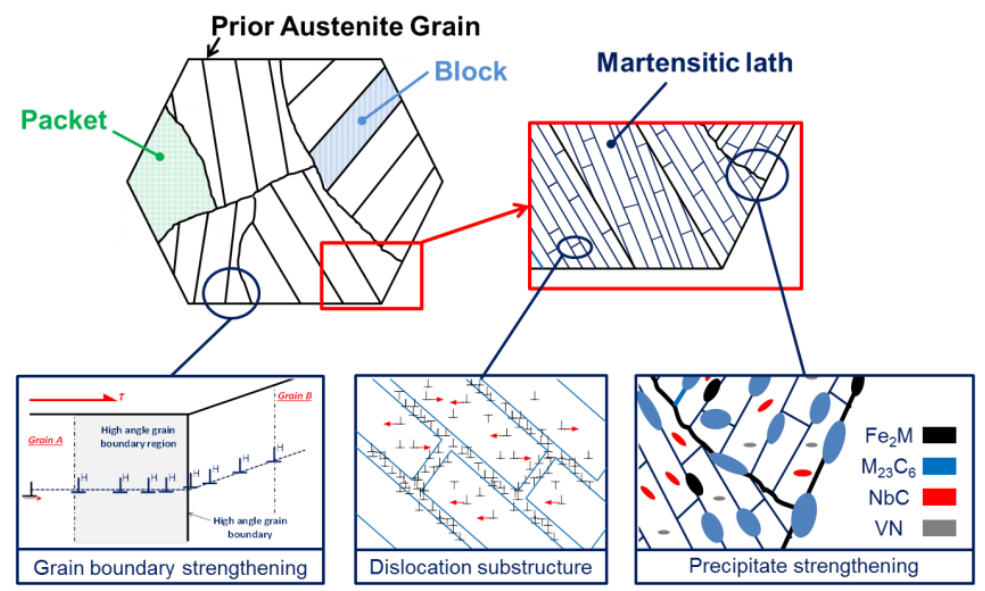

Fig. 2. Schematic microstructure and key strengthening mechanisms in $9 \% \mathrm{Cr}$ steel [30]

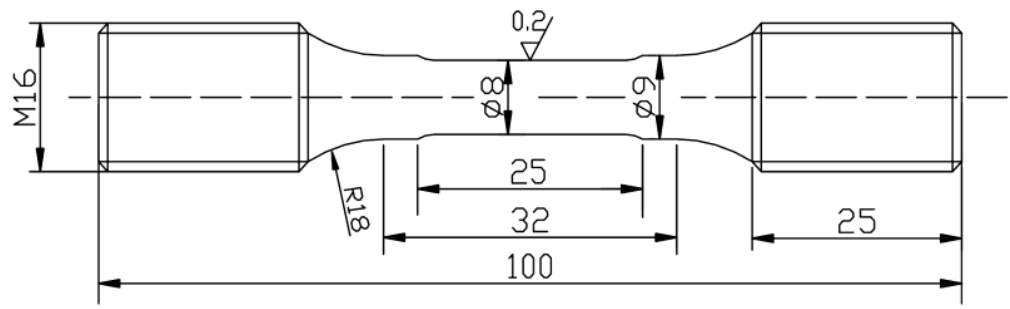

Fig. 3. Specimen geometry for C-F followed by tensile and creep tests (unit: $\mathrm{mm}$ ) 


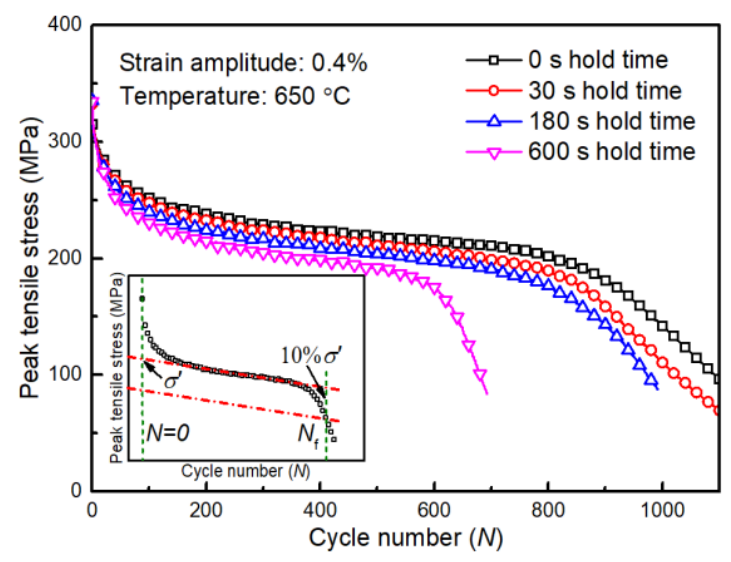

Fig. 4. Cyclic softening curves of different hold times C-F tests and determination of C-F lifetime

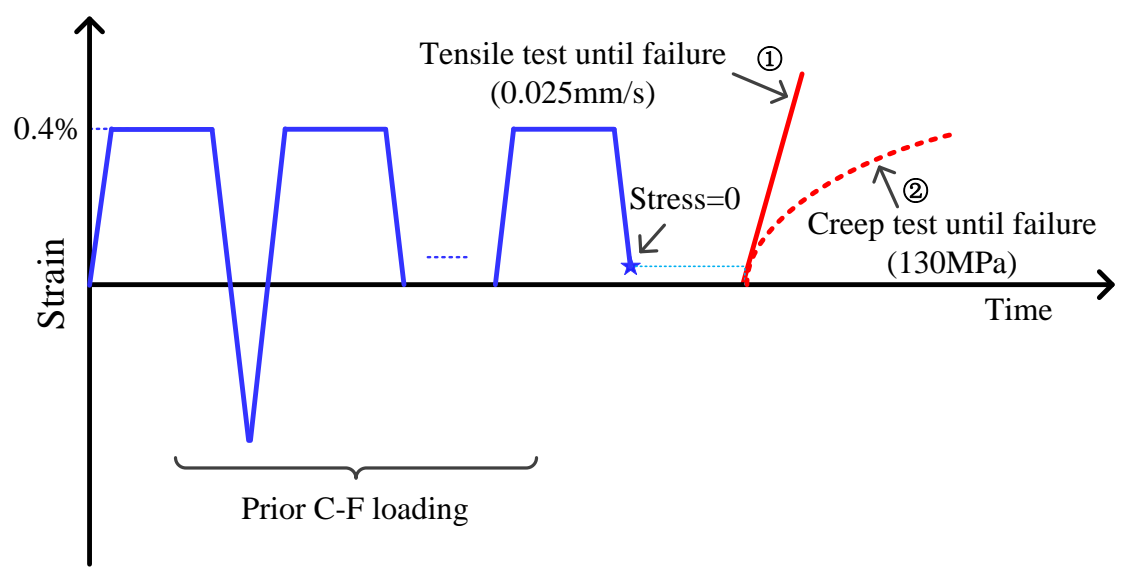

Fig. 5. Schematic representation of interrupted prior C-F test and subsequent tensile and creep tests 

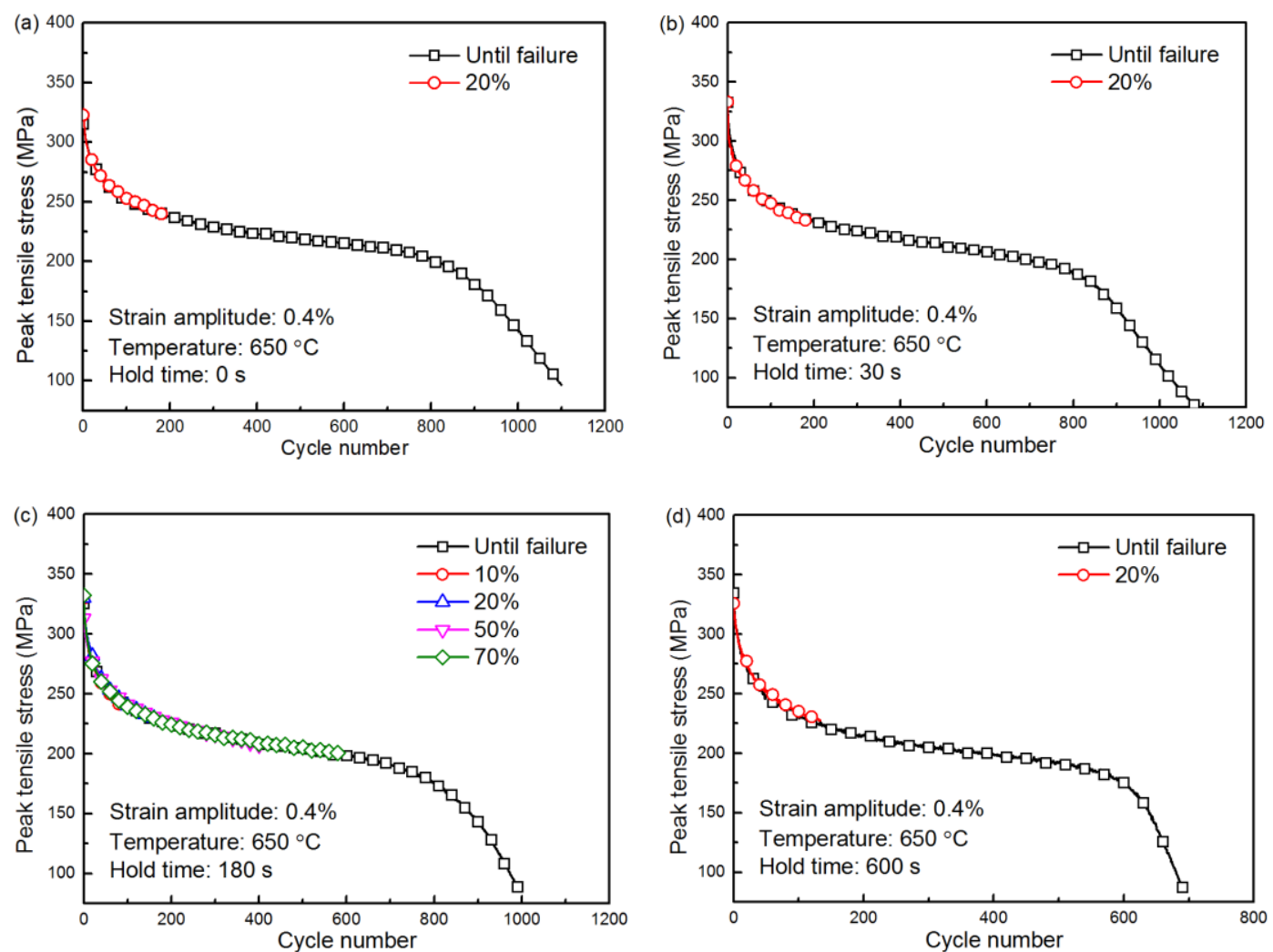

Fig. 6. Evolution of peak tensile stress during prior C-F at different lifetime fractions of different hold times: (a) 0

s, (b) $30 \mathrm{~s}$, (c) $180 \mathrm{~s},(\mathrm{~d}) 600 \mathrm{~s}$ 

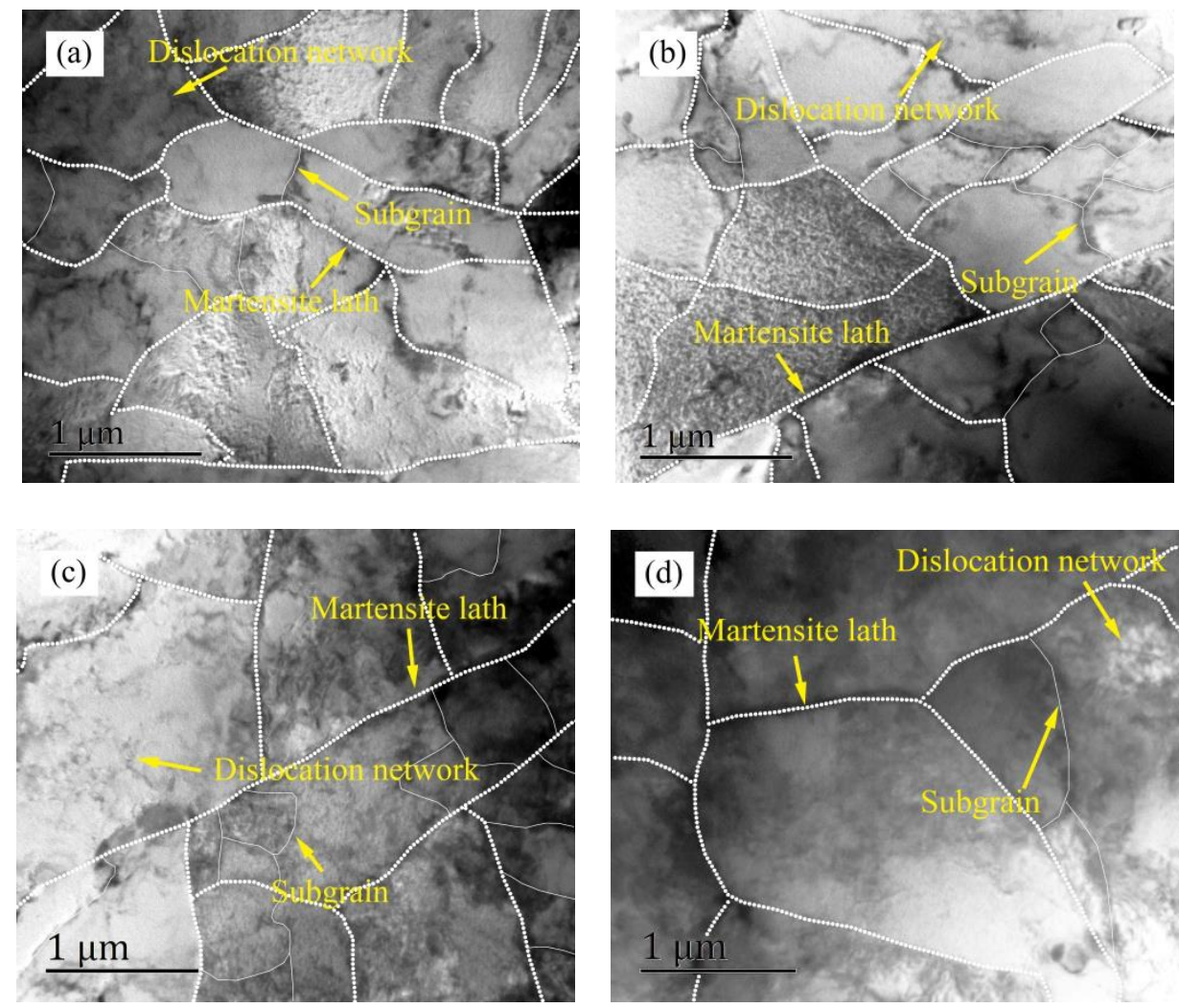

Fig. 7. TEM micrographs of interrupted specimens at different lifetime fractions of 180 s hold time: (a) 10\%, (b) $20 \%$, (c) $50 \%$, (d) $70 \%$
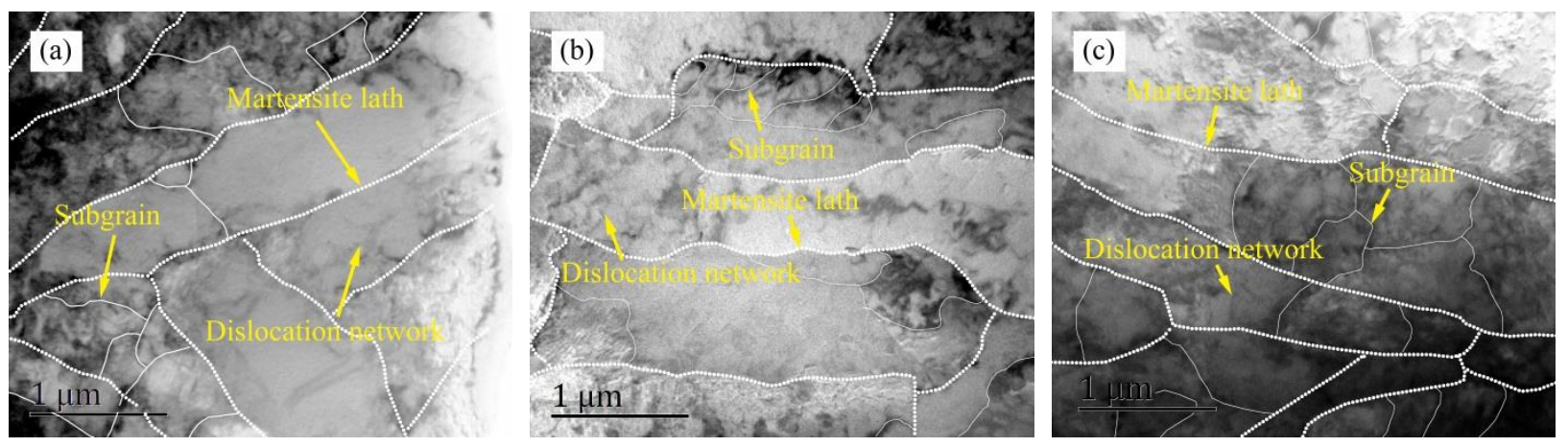

Fig. 8. TEM micrographs of interrupted specimens at $20 \%$ lifetime fraction of different hold times: (a) $0 \mathrm{~s}$, (b) 30

s, (c) $600 \mathrm{~s}$ 

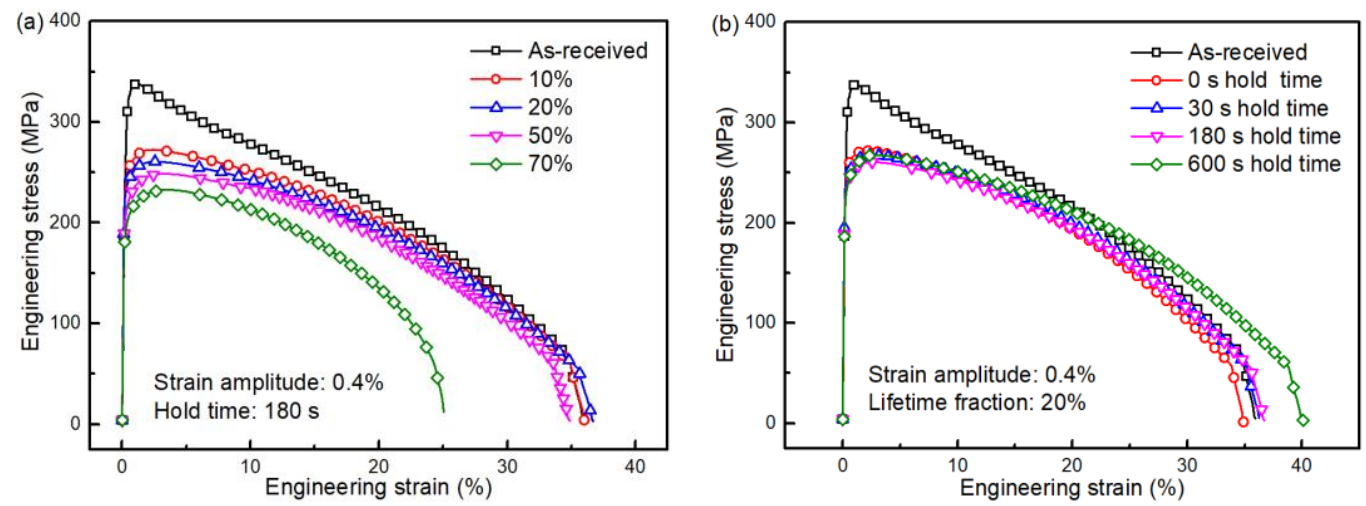

Fig. 9. Tensile curves at (a) different lifetime fractions of $180 \mathrm{~s}$ hold time and (b) $20 \%$ lifetime fraction of different hold times
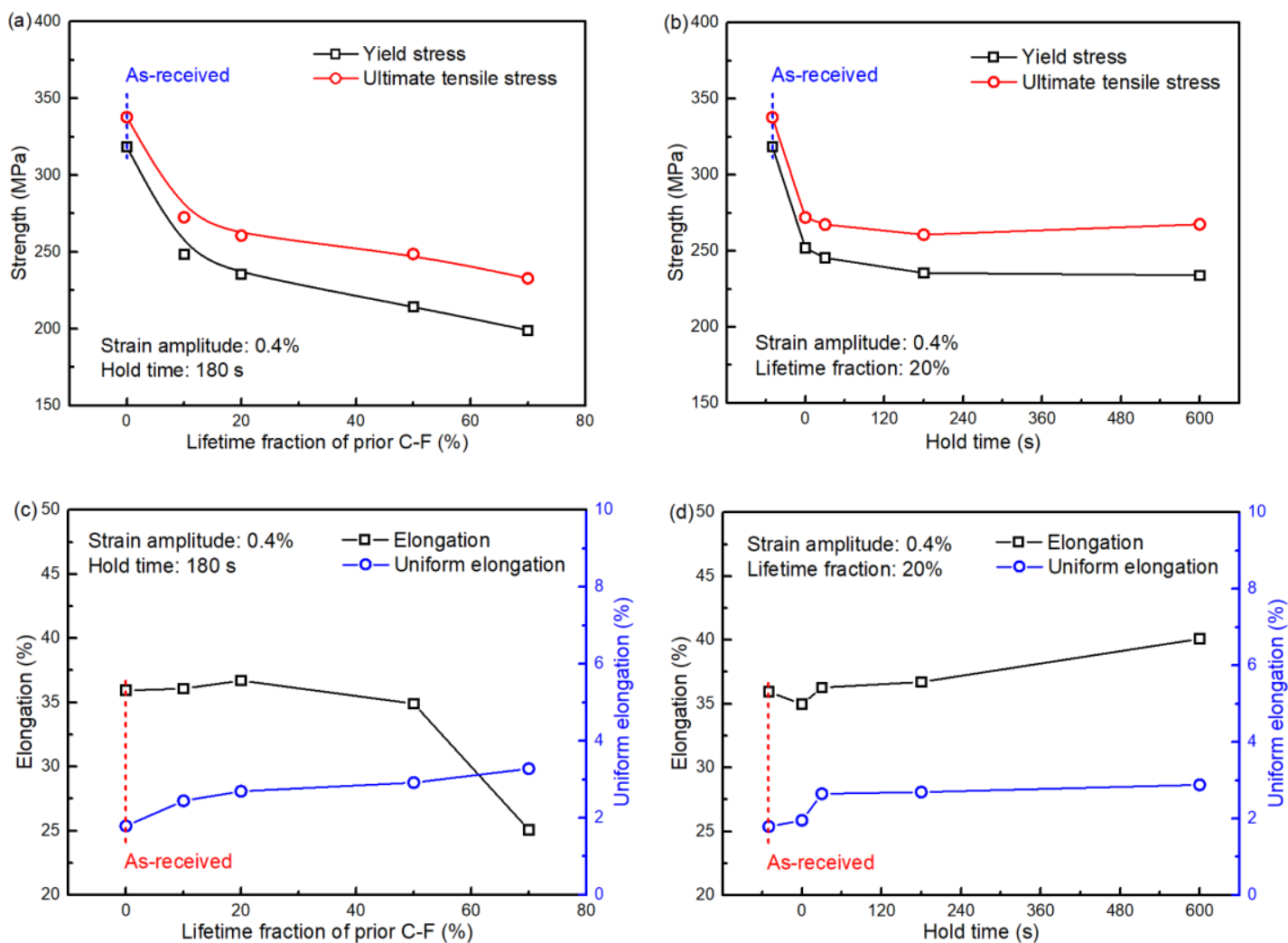

Fig. 10. Tensile strength (a, b) and elongation (c, d) at different lifetime fractions of $180 \mathrm{~s}$ hold time and $20 \%$ lifetime fraction of different hold times 

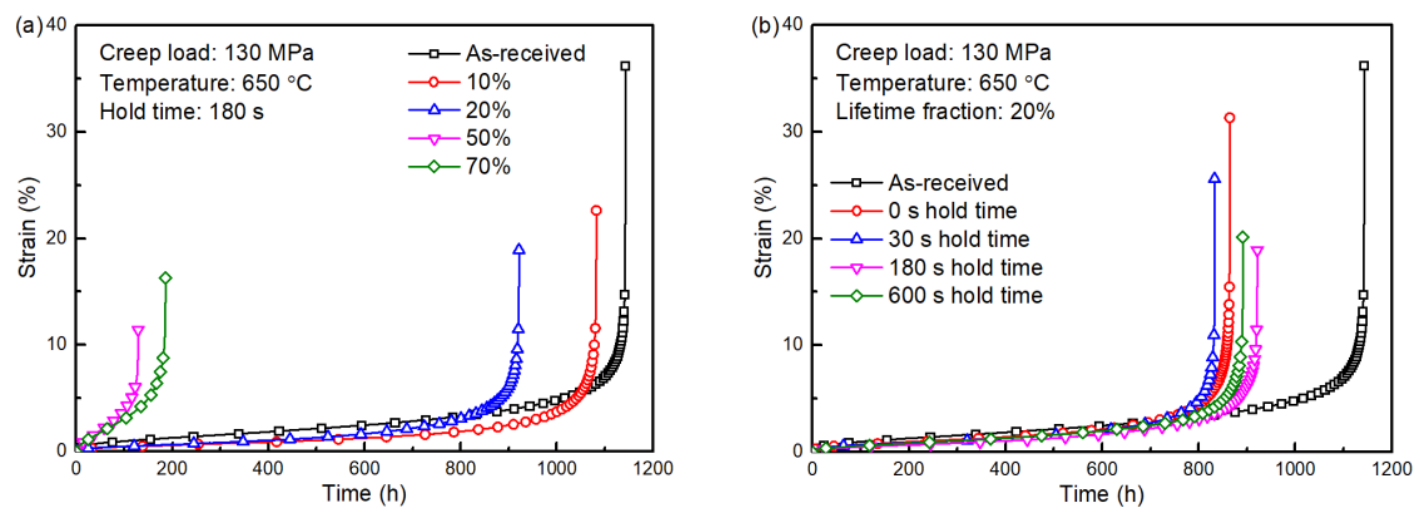

Fig. 11. Creep curves (a) at different lifetime fractions of $180 \mathrm{~s}$ hold time and (b) $20 \%$ lifetime fraction of different hold times
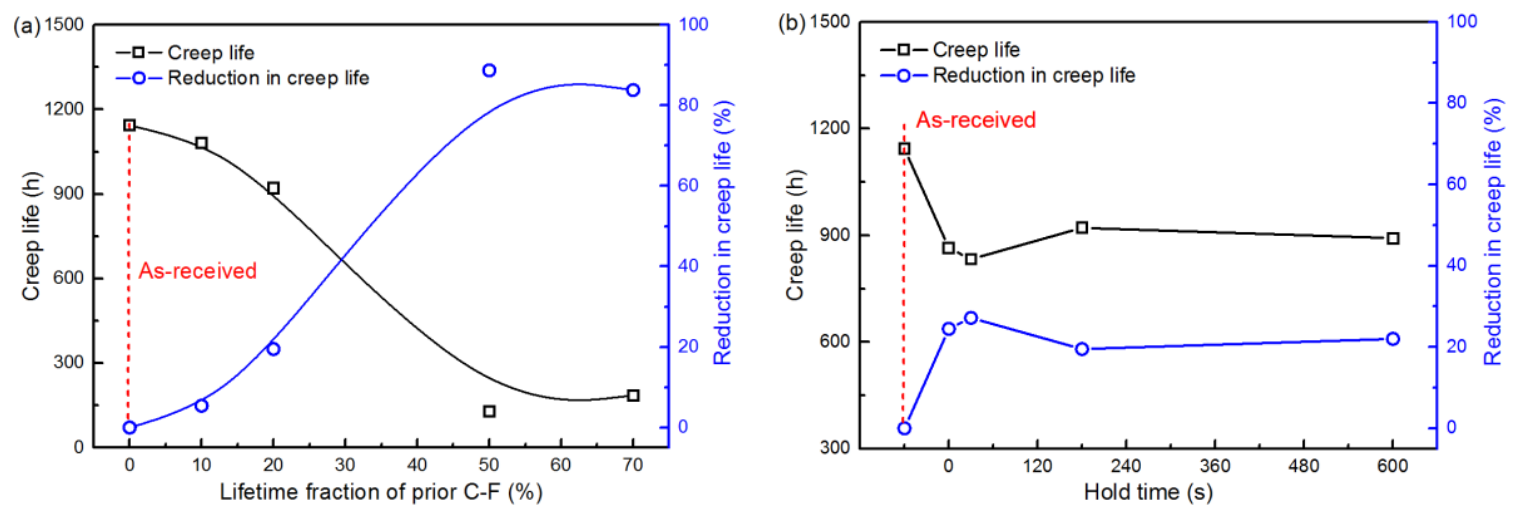

Fig. 12. Creep life at (a) different lifetime fractions of $180 \mathrm{~s}$ hold time and (b) $20 \%$ lifetime fraction of different hold times 

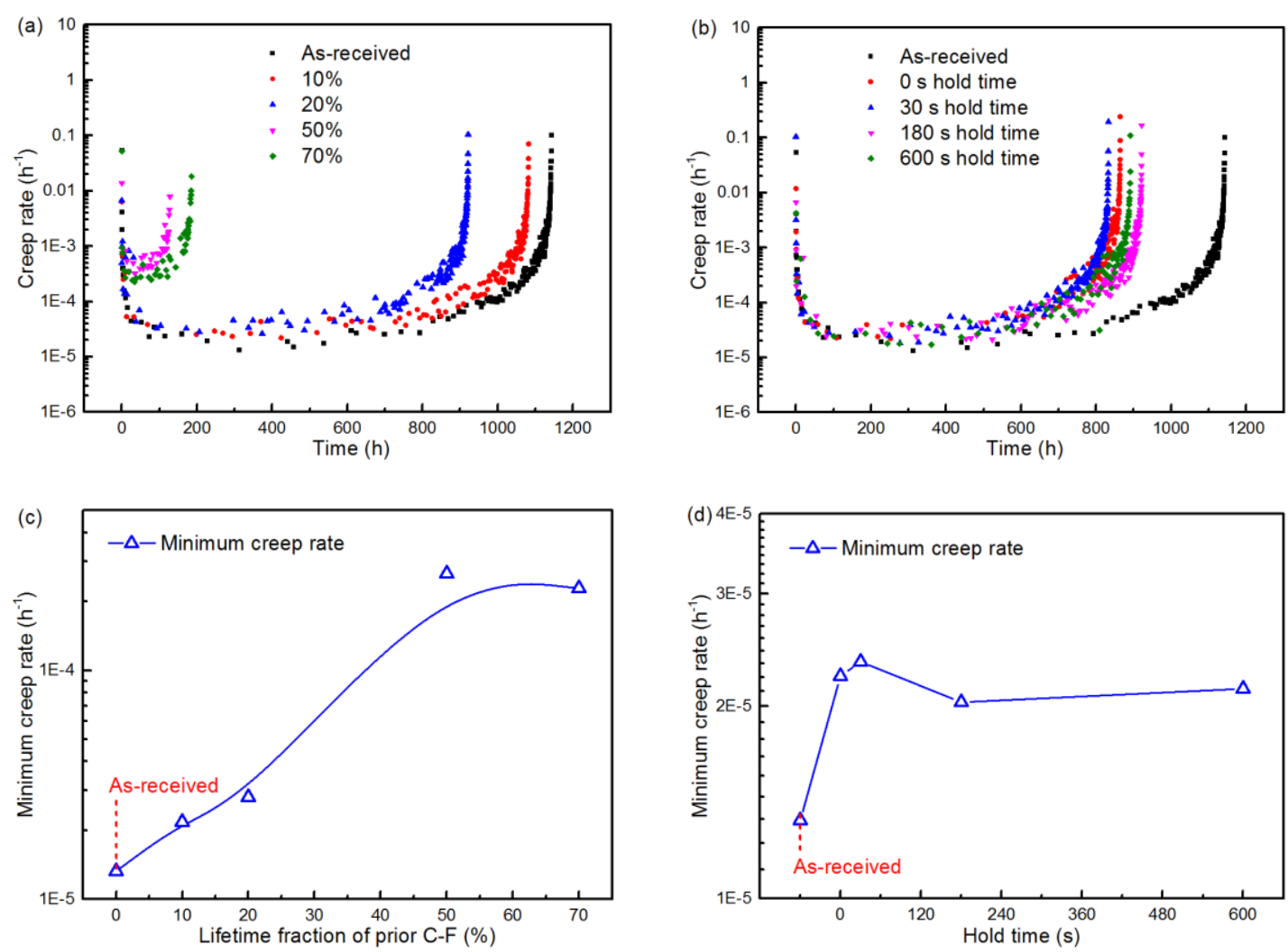

Fig. 13. Creep rate curves $(a, b)$ and the minimum creep rate (c, d) at different lifetime fractions of $180 \mathrm{~s}$ hold time and $20 \%$ lifetime fraction of different hold times 

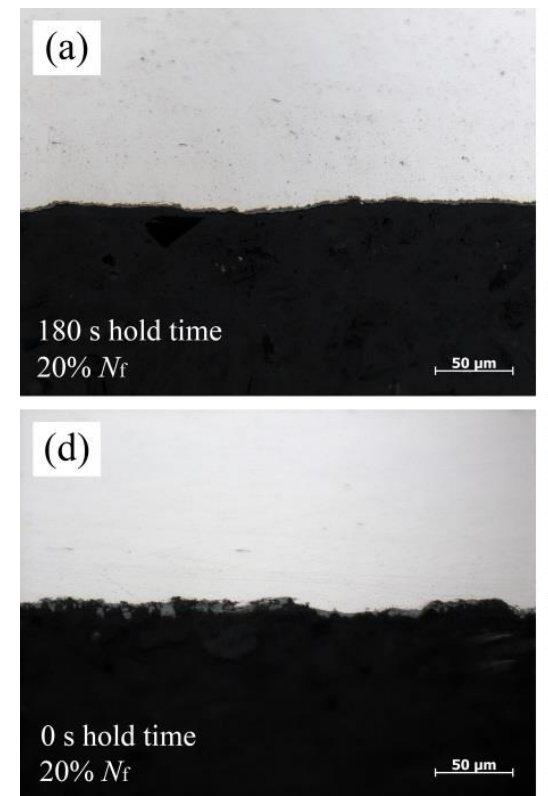

(b)

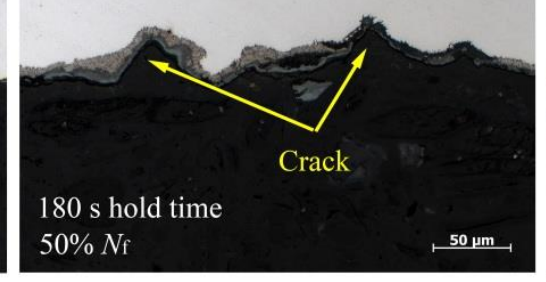

(e)

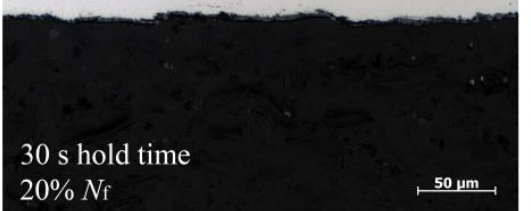

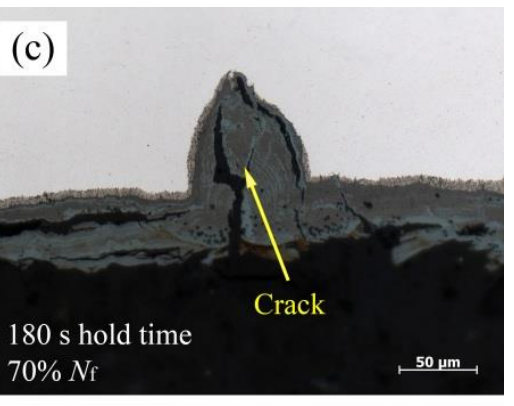

(f)

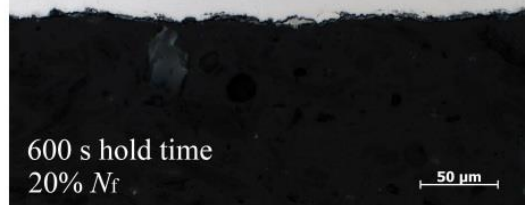

Fig. 14. Outer surface micrographs of the tensile failed specimens near the fracture location under various prior C-F loadings: (a) 20\% lifetime of $180 \mathrm{~s}$ hold time, (b) 50\% lifetime of $180 \mathrm{~s}$ hold time, (c) $70 \%$ lifetime of $180 \mathrm{~s}$ hold time, (d) $20 \%$ lifetime of $0 \mathrm{~s}$ hold time, (e) $20 \%$ lifetime of $30 \mathrm{~s}$ hold time, (f) $20 \%$ lifetime of $600 \mathrm{~s}$ hold time

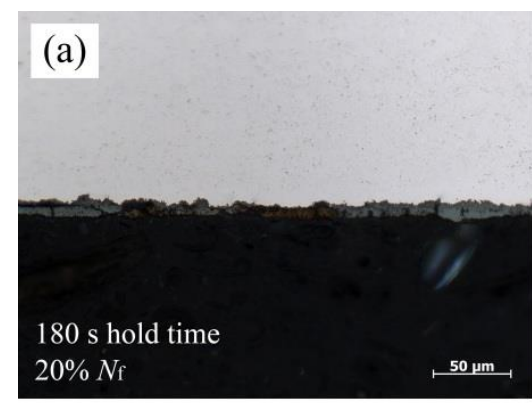

(d)

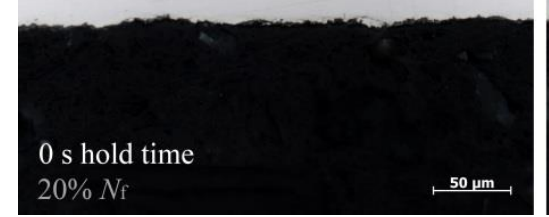

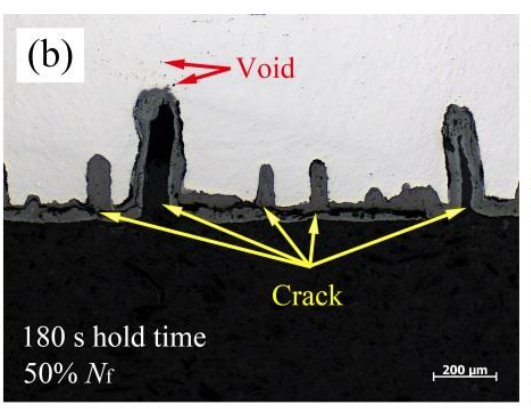

(e)

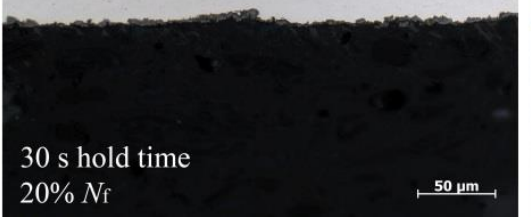

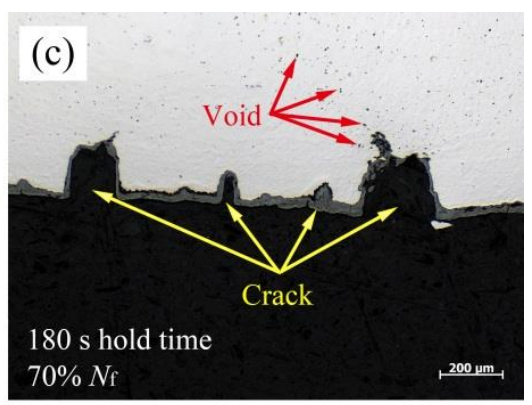

(f)

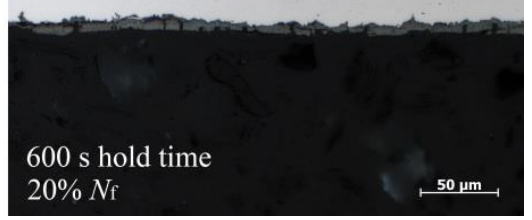

Fig. 15. Outer surface micrographs of the creep failed specimens near the fracture location under various prior C-F loadings: (a) 20\% lifetime of $180 \mathrm{~s} \mathrm{hold} \mathrm{time,} \mathrm{(b)} 50 \%$ lifetime of $180 \mathrm{~s}$ hold time, (c) $70 \%$ lifetime of $180 \mathrm{~s}$ hold time, (d) $20 \%$ lifetime of $0 \mathrm{~s}$ hold time, (e) $20 \%$ lifetime of $30 \mathrm{~s}$ hold time, (f) $20 \%$ lifetime of $600 \mathrm{~s}$ hold time 

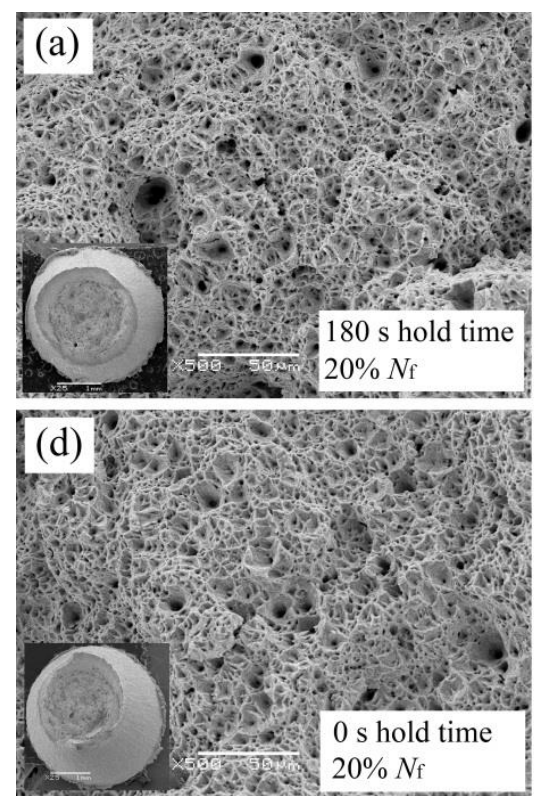
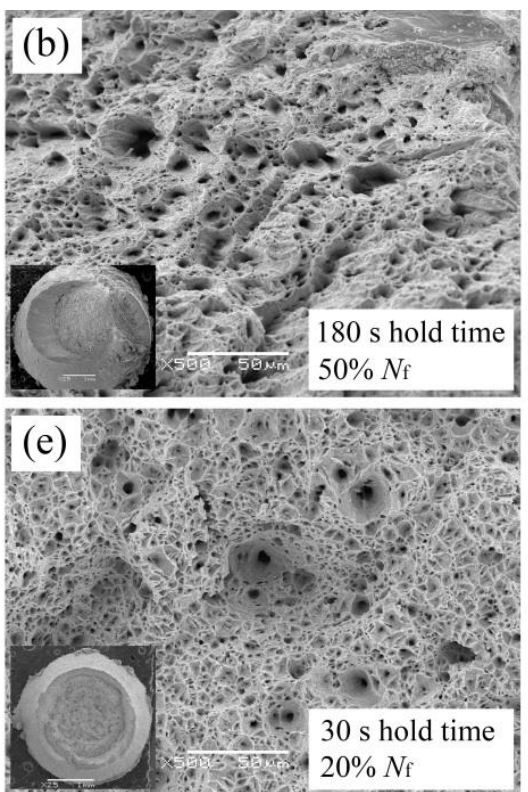
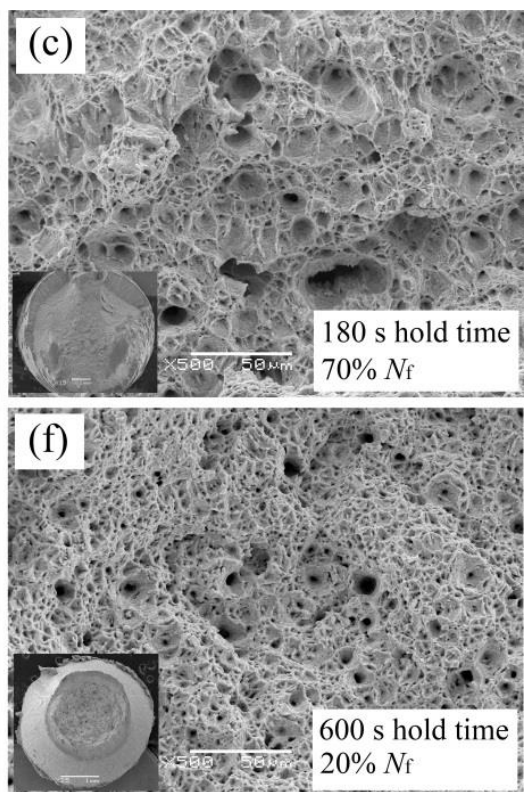

Fig. 16. Fractographs of the tensile failed specimens under various prior C-F loadings: (a) $20 \%$ lifetime of $180 \mathrm{~s}$ hold time, (b) $50 \%$ lifetime of $180 \mathrm{~s}$ hold time, (c) $70 \%$ lifetime of $180 \mathrm{~s}$ hold time, (d) $20 \%$ lifetime of $0 \mathrm{~s}$ hold time, (e) $20 \%$ lifetime of $30 \mathrm{~s}$ hold time, (f) $20 \%$ lifetime of $600 \mathrm{~s}$ hold time
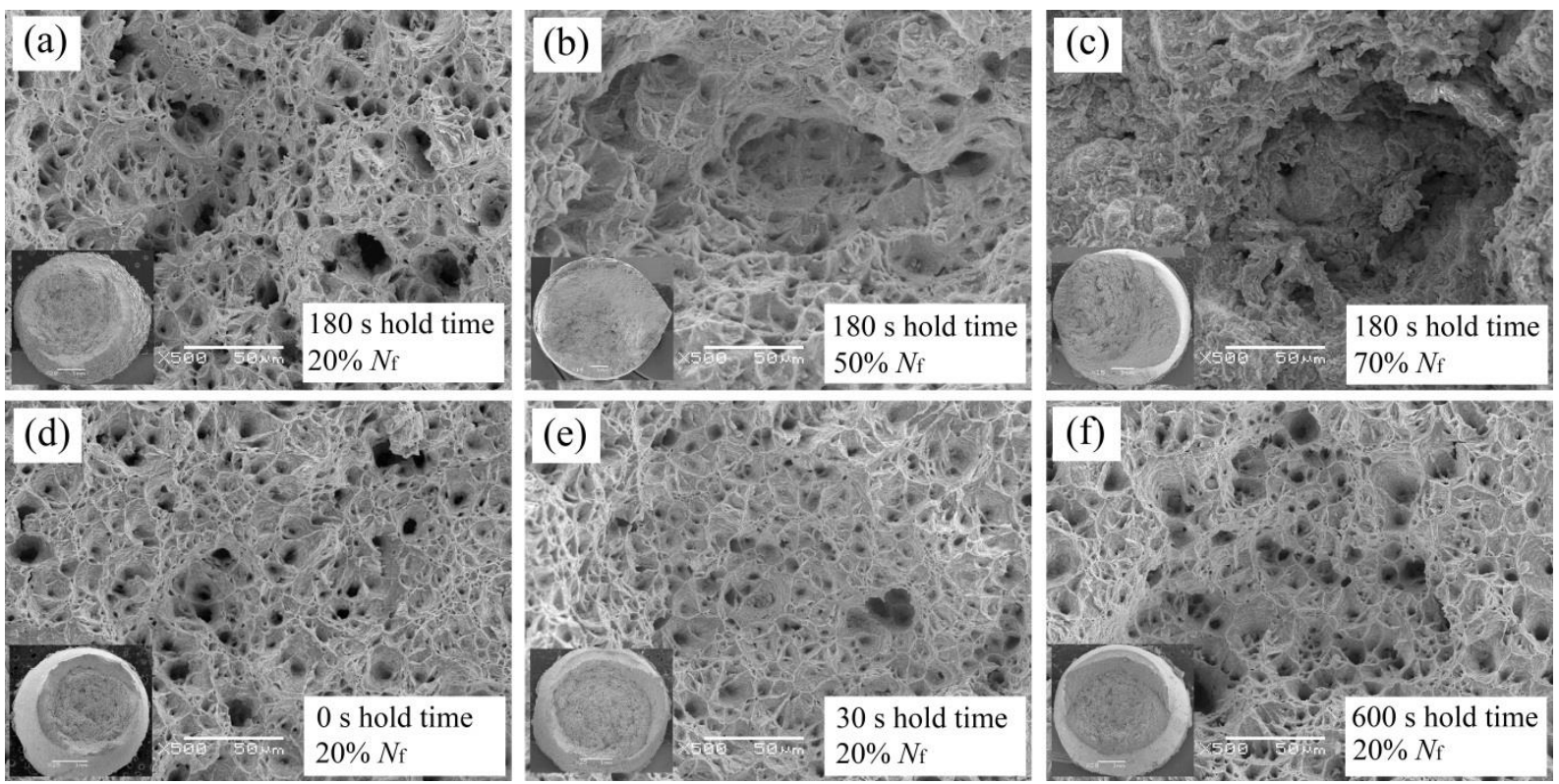

Fig. 17. Fractographs of the creep failed specimens under various prior C-F loadings: (a) $20 \%$ lifetime of $180 \mathrm{~s}$ hold time, (b) $50 \%$ lifetime of $180 \mathrm{~s}$ hold time, (c) $70 \%$ lifetime of $180 \mathrm{~s}$ hold time, (d) $20 \%$ lifetime of $0 \mathrm{~s}$ hold time, (e) $20 \%$ lifetime of $30 \mathrm{~s}$ hold time, (f) $20 \%$ lifetime of $600 \mathrm{~s}$ hold time 

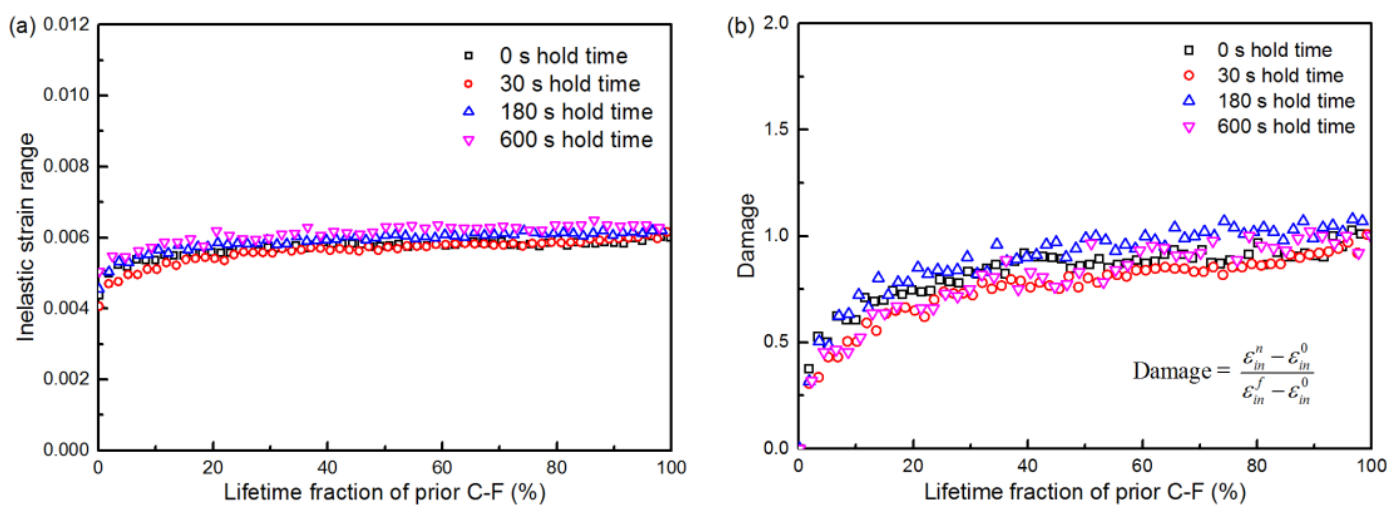

Fig. 18. Evolution of (a) inelastic strain range and (b) defied fatigue damage during C-F process
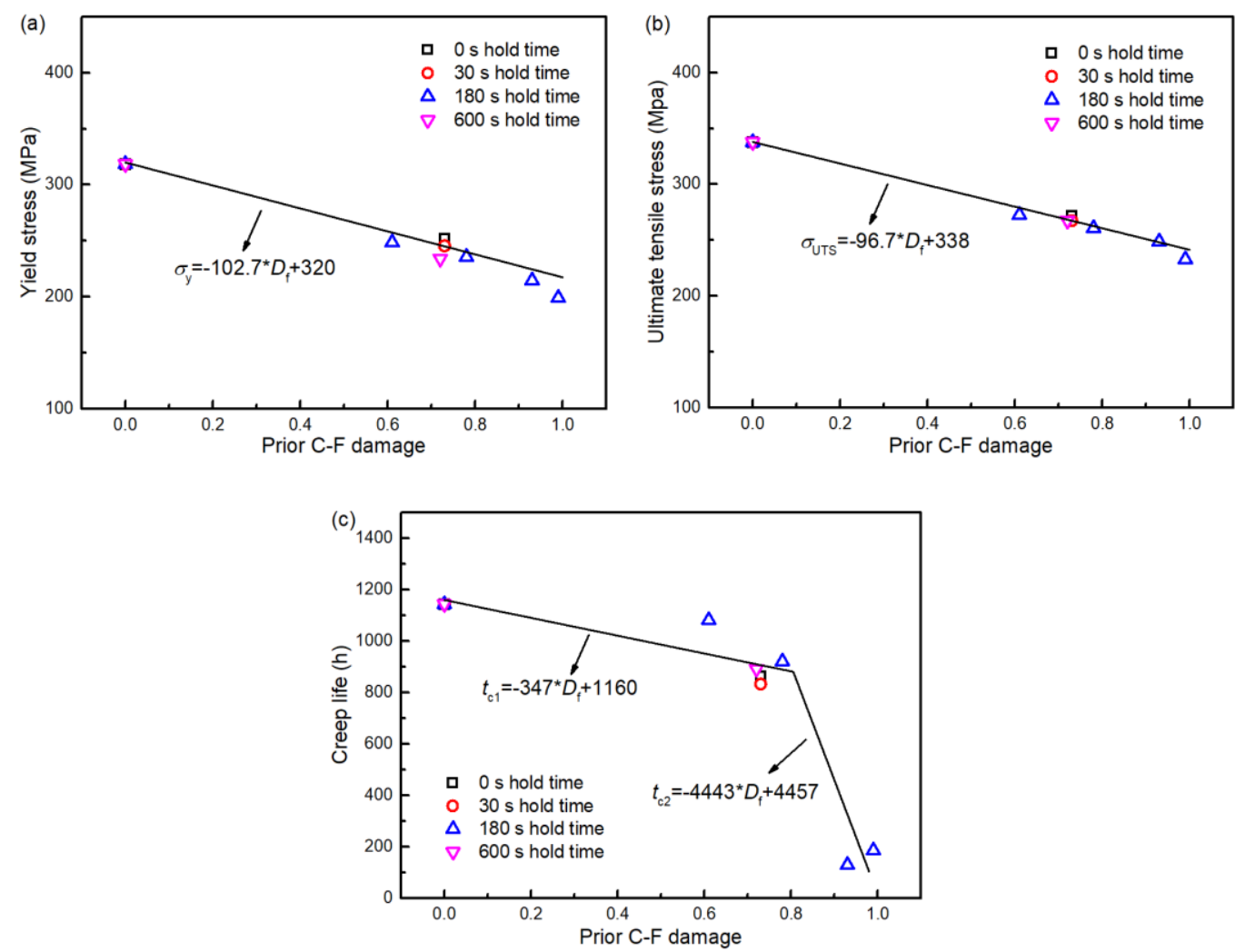

Fig. 19. The relationship between (a) yield stress, (b) ultimate tensile stress and (c) creep life with the defined prior C-F damage 

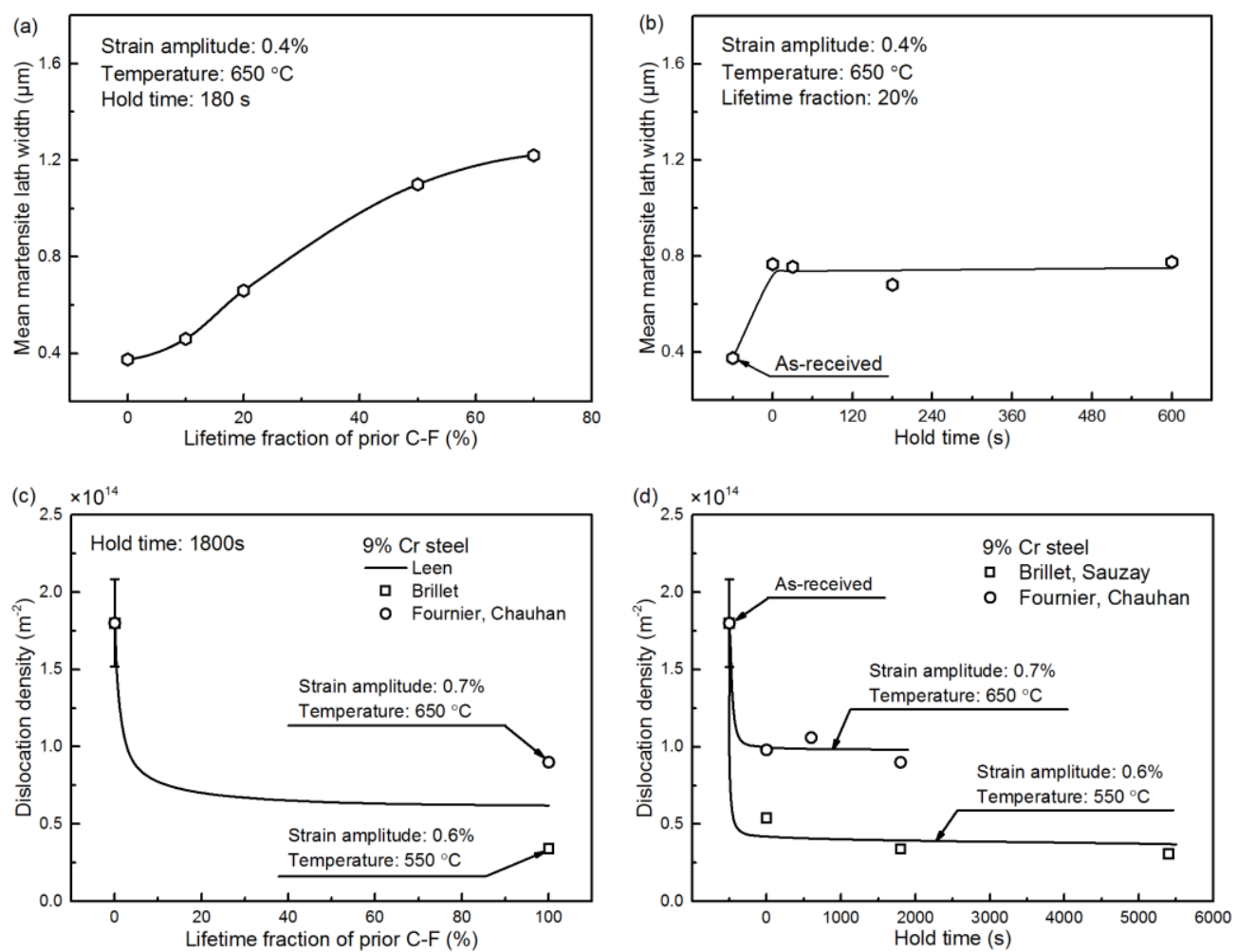

Fig. 20. Evolution of (a, b) martensite lath width and (c, d) dislocation density [30, 52, 56, 57-61] at different lifetime fractions and different hold times
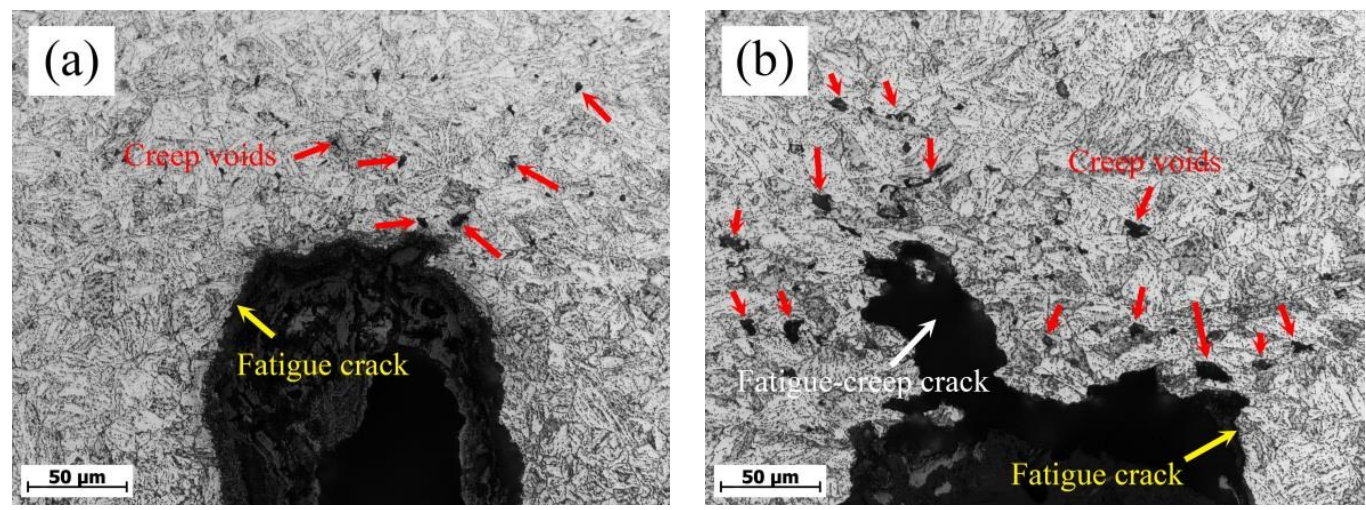

Fig. 21. Local magnification micrograph of the creep failed specimens near the fracture location under various prior C-F loadings: (a) 50\% lifetime of $180 \mathrm{~s}$ hold time, (b) $70 \%$ lifetime of $180 \mathrm{~s} \mathrm{hold} \mathrm{time}$ 

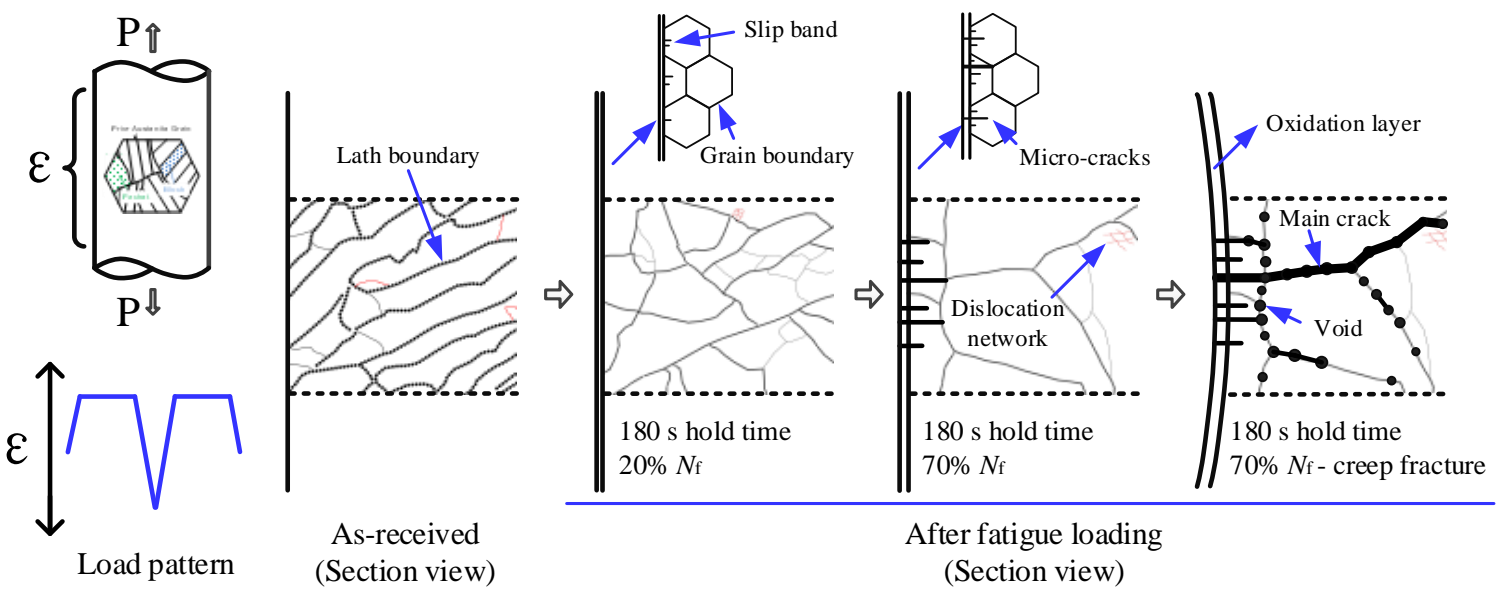

Fig. 22. Schematic representation of prior C-F and subsequent creep damage mechanisms 